\title{
Review Article \\ Some Experimental Investigations on Gas Turbine Cooling Performed with Infrared Thermography at Federico II
}

\author{
T. Astarita, G. Cardone, L. de Luca, and G. M. Carlomagno \\ University of Naples Federico II, Piazzale le Tecchio 80, 80125 Napoli, Italy \\ Correspondence should be addressed to G. M. Carlomagno; carmagno@unina.it
}

Received 17 October 2014; Accepted 6 January 2015

Academic Editor: Tariq Iqbal

Copyright ( 2015 T. Astarita et al. This is an open access article distributed under the Creative Commons Attribution License, which permits unrestricted use, distribution, and reproduction in any medium, provided the original work is properly cited.

\begin{abstract}
This paper reviews some experimental measurements of convective heat transfer coefficient distributions which are connected with the cooling of gas turbines, performed by the authors' research group at the University of Naples Federico II with infrared thermography. Measurements concern impinging jets, cooling of rotating disks, and gas turbine blades, which are either stationary or rotating. The heated thin foil sensor, associated with the detection of surface temperature by means of infrared thermography, is exploited to accurately measure detailed convective heat transfer coefficient maps. The paper also intends to show how to correctly apply the infrared technique in a variety of gas turbines cooling problems.
\end{abstract}

\section{Introduction}

The establishment of gas turbine engines dates back to the forties and, since then, the gas highest absolute temperature more than doubled, going from around $1000 \mathrm{~K}$ to over $2000 \mathrm{~K}$. This temperature increase was required by the need to improve the efficiency of the engine thermodynamic cycle and, consequently, of the overall engine performance [1].

Currently, the temperatures reached are well in excess of those at which creeping (as well as thermal oxidation, melting, spallation, crack formation, etc.) of the leading nickel base superalloys, from which some components are generally made, occurs. Whilst some of the increase of the turbine entry temperature was made possible through the use of more sophisticated materials, a great part of it was made possible because of the developments in turbine component cooling technology. In fact, to reduce the temperature of these components, a certain amount of air is extracted from the HP compressor and used to cool HP turbine nozzle guide vanes and rotating blades, seal segments, and disks the blades are attached to.

The use of turbine cooling flows may appear to be quite a restricted strategy since cooling flows basically represent losses in the thermodynamic cycle and increasing them may eventually lead to thermal efficiency deficits. Nevertheless, cooling will be essential until the introduction of new materials, such as ceramics, will become a major reality. However, a lot more research is required before this goal is fully achieved.

In [1] of 2011, it is reported that, despite the relatively low improvement rate in turbine material technology (which can be roughly estimated to be approximately $3 \mathrm{~K} /$ year), engine designs have undergone substantial increases of the turbine entry temperature over the past 60 years (of the order of $10 \mathrm{~K} /$ year). This is illustrated in Figure 1 for engines designed for long-haul applications. The main reasons behind this temperature increase are, firstly, the introduction of cooling, which produced an initial abrupt rise, and secondly to improve cooling efficiency not to mention the introduction of thermal barrier coatings and single crystal blade castings.

Because of cycle efficiency reasons, the maximum temperature increase is accompanied by a growth in the engine compression ratio which, consequently, leads to an increase in the initial temperature of the cooling air (up to about $700^{\circ} \mathrm{C}$ ). In addition, due to their common origin in the final stage of the HP compressor, this air is at a pressure which is not much higher than that of the hot gas stream at the turbine initial stage. The pressure margin of the cooling air is, therefore, relatively small and cooling must necessarily be performed by means of enhanced heat transfer. 


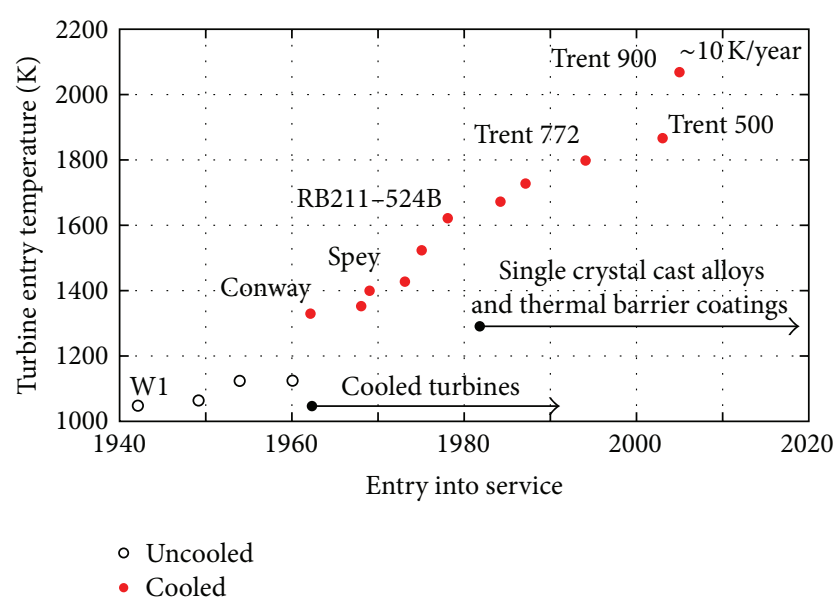

Figure 1: Turbine entry temperature versus date of entry into service. Adapted from Kyprianidis [1].

Several methods of gas turbines cooling have been considered in the past and the most efficient of them are still in use in modern engines. Typically, the critical components are cooled internally and externally by using the cooling air extracted from the compressor final stage. For example, high-pressure turbine rotor blades have internal serpentine labyrinths of passages through which the cooling air goes before being vented to the external blade surface. Often, this latter occurs via an array of tiny holes along and around its hottest areas. In this way, the air, emerging with velocity, of the order of the mainstream flow, forms a film of colder fluid around the blade surface (film cooling), thereby insulating it from the hot gases.

From a basic engineering point of view, the parameters the designer has to face are basically the stress levels, due to both mechanical and thermal loads, and the fatigue life of each component. However, these parameters can be only dealt with on the basis of a detailed evaluation of the local temperature distribution in the component under scrutiny which, in turn, requires the knowledge of the local convective heat transfer coefficients (internal and external) for different operating conditions.

Of course, research on gas turbine engines is also extensively oriented towards the reduction of noise and emissions produced by the ever increasing global air traffic although this is not of interest within the present context.

Following on from and developing on a previous article on the same subject [2], this paper describes some detailed measurements of the convective heat transfer coefficient distribution, performed by the authors' research group, in some complex fluid flows related to the cooling of both stationary and rotating gas turbine components. The heated thin foil sensor, together with detection of surface temperature by means of infrared (IR) thermography, is exploited to accurately measure such a coefficient. After educing the basic principles that make IR thermography work and of the employed heat flux sensor, several applications, mainly dedicated to gas turbine cooling, are presented and discussed.

\section{Experimental Technique}

2.1. Infrared Thermography. Infrared thermography is based on radiation heat transfer, which is an energy transport mechanism that occurs under the form of electromagnetic waves. By way of this heat transfer mode, energy can also travel in vacuum and may partially be absorbed and reflected by a body or even pass through it [3]. If the intensity of radiation is put at equal to unity and by denoting by $\alpha_{r}(\lambda)$ the fraction being absorbed by the body, with $\rho_{r}(\lambda)$ the fraction being reflected by it and with $\tau_{r}(\lambda)$ the fraction which is being transmitted (which passes through the body), energy conservation requires

$$
\alpha_{r}(\lambda)+\rho_{r}(\lambda)+\tau_{r}(\lambda)=1,
$$

where $\alpha_{r}, \rho_{r}$, and $\tau_{r}$ are, respectively, called absorptivity, reflectivity, and transmissivity coefficients of the body under consideration. These coefficients may depend on both radiation wavelength (spectral) and propagation direction (directional).

Radiation is emitted by all bodies at an absolute temperature $T>0$ and, for nontransparent bodies (opaque, $\tau_{r}=0$ ), it originates only from their surface. The body which emits the greatest amount of energy at a given temperature is called black body.

The law prescribing the energy flux (energy rate per unit area) per wavelength (spectral hemispherical emissive power) emitted by a black body $I_{b}(\lambda)\left(\mathrm{W} / \mathrm{m}^{3}\right)$ is the Planck law of radiation:

$$
I_{b}(\lambda)=\frac{C_{1}}{\lambda^{5}\left(e^{C_{2} / \lambda T}-1\right)},
$$

where $\lambda$ is the radiation wavelength $(\mathrm{m}), T$ is the absolute black body temperature $(\mathrm{K})$, and $C_{1}$ and $C_{2}$ are the first and the second universal radiation constants, equal, respectively, to $3.7418 \times 10^{-16} \mathrm{Wm}^{2}$ and $1.4388 \times 10^{-2} \mathrm{Km}$. Equation (2) shows that $I_{b}$ goes to zero for both $\lambda \rightarrow 0$ and $\lambda \rightarrow \infty$.

The electromagnetic spectrum is roughly divided into a number of wavelength bands. The infrared spectral band, of interest within the present context, is generally subdivided into four lesser bands with arbitrarily chosen boundaries: near infrared $(0.75 \div 3 \mu \mathrm{m})$, middle infrared $(3 \div 6 \mu \mathrm{m})$, far (or long) infrared $(6 \div 15 \mu \mathrm{m})$, and extreme infrared (15 $\div$ $1000 \mu \mathrm{m})$. Most of currently used IR cameras are sensitive in the middle (MWIR) and the far (LWIR) spectral bands.

By deriving and integrating it with respect to $\lambda$, Planck law leads to the following two laws.

(i) Wien Displacement Law. The wavelength $\lambda^{m}$ at which the black body emits its maximum spectral emissive power is a function of the absolute black body temperature $T$ according to

$$
\lambda^{m} T=2897.8 \mu \mathrm{m}-\mathrm{K}
$$


that is, the maximum value of $I_{b}$ moves towards shorter wavelengths as the temperature increases.

(ii) Stefan-Boltzmann Law. The total (overall wavelengths) hemispherical emissive power $E_{b}\left(\mathrm{~W} / \mathrm{m}^{2}\right)$ also depends on the absolute black body temperature alone:

$$
E_{b}=\sigma T^{4}
$$

where $\sigma$ is the Stefan-Boltzmann constant, which is equal to $5.6704 \times 10^{-8} \mathrm{~W} /\left(\mathrm{m}^{2} \mathrm{~K}^{4}\right)$.

Since infrared camera detectors capture only a relatively narrow band of the whole electromagnetic spectrum, Planck law (2), rather than Stefan-Boltzmann law (4), has to be applied in IR thermography.

Real objects almost never comply with the above described laws even if they may approach black body behaviour in certain spectral bands and conditions. A real object generally emits only fraction $I(\lambda)$ of the radiation emitted by the black body $I_{b}(\lambda)$, at the same temperature and wavelength, by introducing the spectral emissivity coefficient, defined as

$$
\varepsilon(\lambda)=\frac{I(\lambda)}{I_{b}(\lambda)} .
$$

Equation (2) can be rewritten for real bodies by simply multiplying its second term by $\varepsilon(\lambda)$ :

$$
I(\lambda)=\varepsilon(\lambda) \frac{C_{1}}{\lambda^{5}\left(e^{C_{2} / \lambda T}-1\right)} .
$$

Kirchhoff law states that the spectral emissivity coefficient $\varepsilon(\lambda)$, which is the fraction of radiation at wavelength $\lambda$ emitted by a body, is equal to the spectral absorptivity coefficient $\alpha_{r}(\lambda)$ at the same wavelength. So, for nontransparent bodies, such as those which are mainly used in infrared thermography, (1) becomes

$$
\varepsilon(\lambda)+\rho_{r}(\lambda)=1 \text {. }
$$

Therefore, materials with low emissivity $\varepsilon$ (such as shining metallic materials) not only emit less energy, but also reflect a large amount of the radiation coming from the ambient and impinging on them. Whenever possible, they should not be employed in IR thermography or, if it is necessary to use them, they have to be lightly sandblasted or else, if transient heat transfer is not implied, covered with a thin layer of thermally black paint (such as white dull enamel).

Besides $I(\lambda)$ being dependent on $\lambda$, real objects almost never emit in a diffuse (isotropic) way, the emissivity coefficient $\varepsilon$ being also dependent on the angle between the direction of emission and the normal to the emitting surface (viewing angle) [3].

Measurement of convective heat fluxes must be performed by means of a heat flux sensor, where proper temperatures have to be measured. By correctly choosing the heat flux sensor, IR thermography can be successfully exploited to resolve convective heat transfer distributions with both steady and transient techniques. When compared to standard

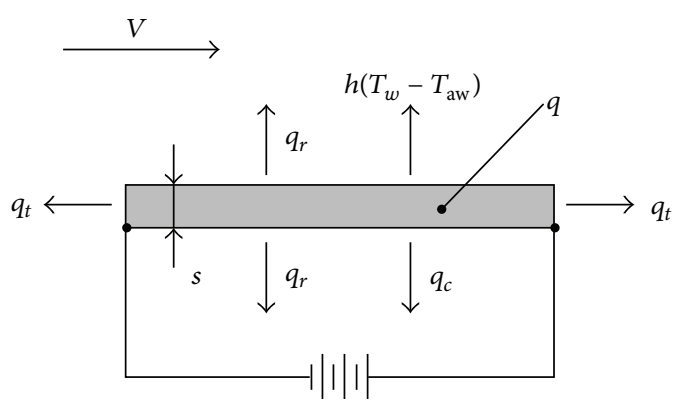

FIGURE 2: Sketch of the heated thin foil sensor with the considered heat fluxes.

transducers, the IR camera appears very valuable because (i) it is nonintrusive, (ii) it has a high sensitivity (down to $20 \mathrm{mK}$ ) and low response time (down to $20 \mu \mathrm{s}$ ), and (iii) it is fully two-dimensional (from $300 \mathrm{k}$ up to $1 \mathrm{M}$ pixels) and so allows for better evaluation of errors, for example, due to tangential conduction within the sensor.

2.2. Steady-State Heated Thin Foil Sensor. Measurement of the local convective heat transfer coefficient can be performed by means of the steady-state heated thin foil sensor associated with the detection of wall temperature by means of an infrared camera $[3,4]$.

The heated thin foil sensor method consists of uniformly heating by Joule effect a thin metallic foil (or a printed circuit board) and of measuring the convective heat transfer coefficient $h$ between the foil and the stream flowing on it by means of the relationship (Newton law):

$$
h=\frac{q-q_{l}}{T_{w}-T_{r}}
$$

where $q$ is the known Joule heating flux $\left(\mathrm{W} / \mathrm{m}^{2}\right) ; q_{l}=q_{t}+$ $q_{c}+q_{r}$ represents heat flux losses which are mainly due to tangential conduction along the foil $q_{t}$, natural convection at the foil back side $q_{c}$, and radiation $q_{r}$ (see Figure 2 ); $T_{w}$ is the wall temperature which is measured by the IR camera when the foil is heated (hot image); $T_{r}$ is a reference temperature. For example, for channel flows, $T_{r}$ coincides with the local bulk temperature or, for relatively high Mach number flows, is the so-called adiabatic wall temperature $T_{\text {aw }}$ [3]. It being possible to neglect $q_{l}, T_{\text {aw }}$ may be detected by measuring the wall temperature of the foil when this latter is not being heated ( $q=0$, cold image).

Generally, the foil should be thermally insulated at its back face, that is, the face opposite to that which the stream is flowing over with velocity $V$. When insulation cannot be accomplished, for example, to measure the temperature distribution over this face, additional thermal losses, such as natural convection and radiation, have also to be taken into account. In fact, it can be readily understood that, if the Biot number, $\mathrm{Bi}=h_{t} s / k_{s}$, is relatively small, the foil can be considered isothermal across its thickness and measurements can be performed on either of the foil's faces.

Often ignored tangential conduction, which modulates the thermal signal, can be evaluated by means of the Laplacian 
of the wall temperature [3]. In principle, this seems relatively easy to perform by considering that the camera provides a very large number of measurement points. However, it has to be stressed that spurious effects, linked to spatial noise, must be avoided by carefully filtering, and/or splining, the temperature signal. Since the sensor is a steady-state one, averaging a large number of thermal images can consistently reduce the temporal noise.

If the heated thin foil is made of a printed circuit board, the bulk tangential thermal conductance along the foil is nonisotropic. In fact, if the circuit is obtained with several electrical conducting tracks arranged in a Greek fret mode, due to the very high thermal conductivity coefficient of copper, the thermal conductance along the tracks is usually significantly higher than that perpendicular to them. This anisotropy may be taken into account by allowing for two different bulk tangential thermal conductances, one along the tracks and the other one perpendicular to them. Further details on the correction of the nonisotropic heated thin foil can be found in Astarita and Carlomagno [3].

The infrared systems used herein are either AGEMA Thermovision 900LW or CEDIP Jade III. In the first, the field of view is scanned by a single detector in the LWIR infrared window; nominal sensitivity (expressed in terms of noise equivalent temperature difference) is $0.07 \mathrm{~K}$ and each thermal image is digitised at 12 bits in a frame of $136 \times$ 272 pixels. The second has a MWIR FPA, $320 \times 240$ pixels, with sensitivity of $0.02 \mathrm{~K}$. For each image, dedicated software is employed which normally involves noise reduction by numerical filtering, computation of temperature maps, and evaluation of radiation and tangential conduction losses as well as heat transfer correlations.

\section{Applications}

In the following, several experimental applications of infrared thermography, regarding gas turbines cooling, are reported. Average data accuracy is of the order of at most $\pm 7 \%$.

3.1. Rotating Disk. The authors apply IR thermography to heat transfer measurements in different rotating disk configurations [5-7] and illustrate the importance of the adiabatic wall temperature $T_{\mathrm{aw}}$ in relatively high Mach number flows.

The experimental apparatus is sketched in Figure 3 and consists of a $450 \mathrm{~mm}$ diameter shallow steel cup (disk), rotating in still air, filled with a $20 \mathrm{~mm}$ thick layer of polyurethane foam on which a printed circuit board is glued. The latter has copper tracks, with a double spiral shape, $35 \mu \mathrm{m}$ thick, $2 \mathrm{~mm}$ wide, and with a $2.5 \mathrm{~mm}$ pitch. The board's overall thickness is about $0.2 \mathrm{~mm}$. Electric power from a stabilized power supply is provided to the tracks via a mercury rotating contact. The disk's angular speed $\omega$ can be varied in the range 100$4400 \mathrm{rpm}$ and is precisely monitored by an optical transducer, speed fluctuations resulting less than $1 \%$. For this section, the nozzle is not present.

The thermogram of Figure 4(a) presents the temperature map of the disk rotating in still air $\left(T_{a}=21.4^{\circ} \mathrm{C}\right)$ at $576 \mathrm{rpm}$ with an imposed Joule heat flux $q=515 \mathrm{~W} / \mathrm{m}^{2}$. Due to disk

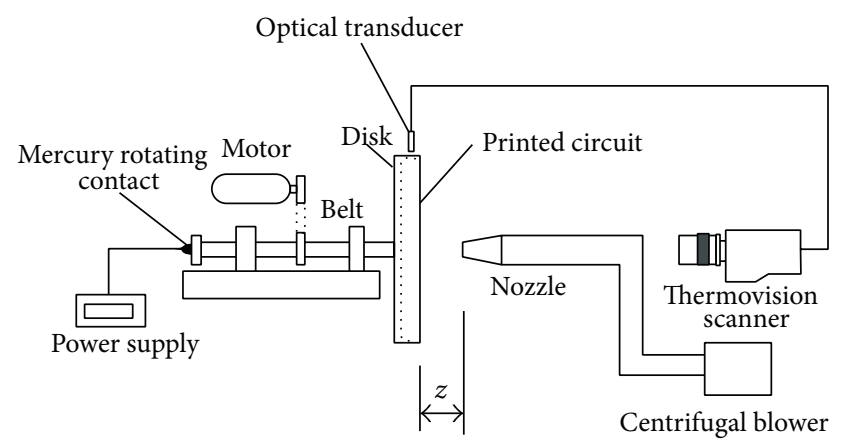

FIgURE 3: Apparatus to study the rotating disk heat transfer with, and without, a centred impinging jet.

rotation, the reported map is practically an azimuthal average of the local wall temperature (this explains its almost perfect symmetry) and, as shown by (8), this map can be interpreted with the inverse proportionality between temperature difference $\left(T_{w}-T_{\mathrm{aw}}\right)$ and convective heat transfer coefficient. Most of the thermogram of Figure 4(a) indicates constant temperature $T_{w}$ over the disk of about $45.6^{\circ} \mathrm{C}$ and this is because, given the relatively low rotating speed, the flow there is laminar.

In fact, it has to be remembered that, for a disk rotating at angular speed $\omega$, the heat transfer solution of Millsaps and Pohlhausen [8] for the heat transfer coefficient in laminar flow is

$$
h=a k \sqrt{\frac{\omega}{v}}
$$

where $v$ and $k$ are the air kinematic viscosity and thermal conductivity coefficients, respectively, and $a$ is a constant, which for air at ambient temperature $(\operatorname{Pr} \approx 0.71)$ turns out to be equal to about 0.33 . Equation (9) shows that $h$ does not depend on the disk radial coordinate $r$. Given that the convective heat transfer coefficient is constant over the central region of the disk surface, from (8) it follows that, for a constant heat flux boundary condition and constant reference temperature $T_{r}=T_{\mathrm{aw}}$ (which in this case is the ambient air temperature $T_{a}$ ), the wall temperature $T_{w}$ also has to be constant. Towards the disk edge, temperature varies rapidly because, as will be shown, $h$ increases rapidly there.

On the other hand, the thermogram of Figure 4(b) shows the temperature map of the same disk rotating at a much higher speed, $4390 \mathrm{rpm}$, with an imposed Joule heat flux $q=$ $871 \mathrm{~W} / \mathrm{m}^{2}$. It will be evidenced that, for the present case, the adiabatic wall temperature plays a significant role in the thermal behaviour of the flow because; if it is not considered, an inconsistency is found.

In fact, in Figure $4(\mathrm{~b})$, a relatively small region $(\approx 16 \%$ of the disk surface), near the disk centre where the flow is still laminar, shows constant temperature $T_{w}$ of about $38.5^{\circ} \mathrm{C}$. Actually, in this central part of the disk, the local tangential speed is relatively small and consequently the flow regime is practically hyposonic (very low Mach number $M$ ), so that the adiabatic wall temperature $T_{\mathrm{aw}}$ essentially coincides with the ambient air temperature $T_{a} \approx 21.4^{\circ} \mathrm{C}$. This is shown in 


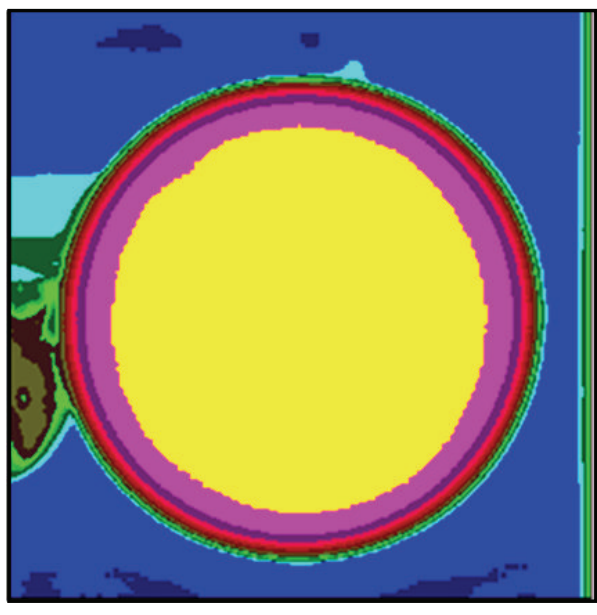

(a)

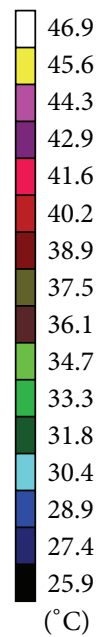

$\left({ }^{\circ} \mathrm{C}\right)$

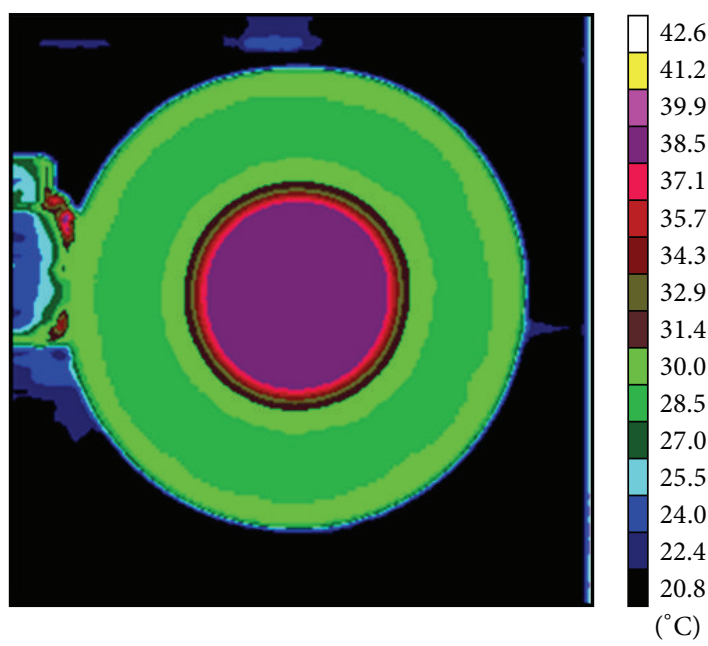

(b)

Figure 4: Temperature map $\left({ }^{\circ} \mathrm{C}\right)$ of the rotating disk for $T_{a}=21.4^{\circ} \mathrm{C}:(\mathrm{a}) \omega=576 \mathrm{rpm}, q=515 \mathrm{~W} / \mathrm{m}^{2}$; (b) $\omega=4390 \mathrm{rpm}, q=871 \mathrm{~W} / \mathrm{m}^{2}$.

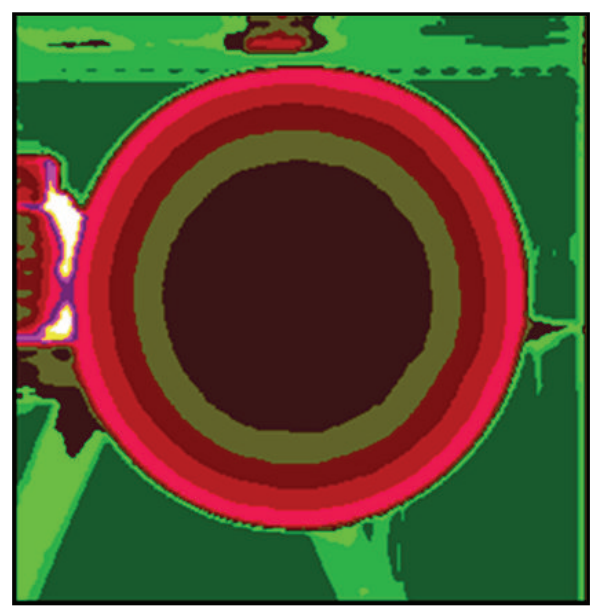

(a)

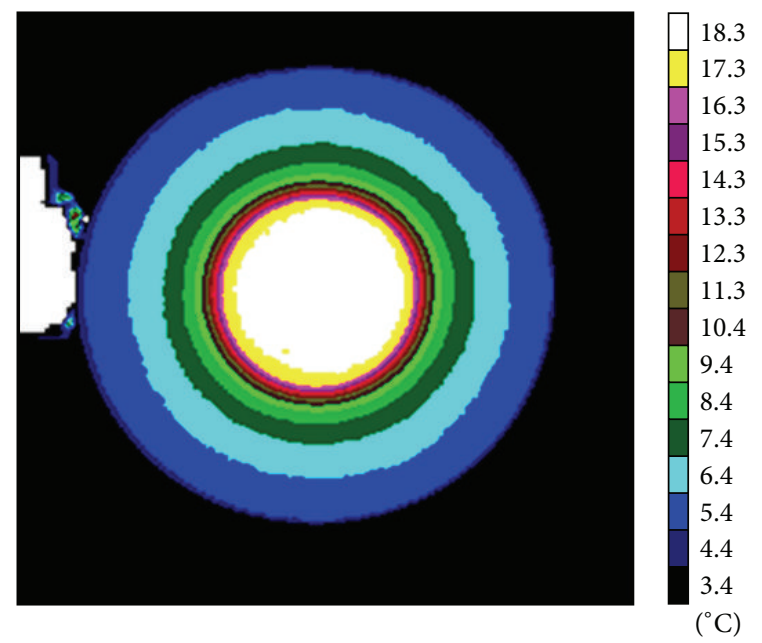

(b)

FIGURE 5: Disk rotating at $4390 \mathrm{rpm}$ : (a) adiabatic wall temperature $T_{\mathrm{aw}}\left({ }^{\circ} \mathrm{C}\right), q=0 \mathrm{~W} / \mathrm{m}^{2}$; (b) temperature difference $T_{w}-T_{\mathrm{aw}}\left({ }^{\circ} \mathrm{C}\right), q=$ $515 \mathrm{~W} / \mathrm{m}^{2}$.

the central part of the thermogram of Figure 5(a), which is obtained by simply making $q=0$ at the same angular speed practically giving, therefore, $T_{\mathrm{aw}}$ as mentioned above. Afterwards, in Figure 4(b), the wall temperature decreases, at first, rapidly and then more slowly. Immediately after, besides some edge effects at disk periphery, the wall temperature trend is reversed as $T_{w}$ slowly rises (medium to light green).

Actually, this temperature increase is explained by looking at the adiabatic wall temperature map of the thermogram of Figure 5(a). In this map, $T_{\mathrm{aw}}$ is practically constant (equal to the ambient air temperature) only within the circumference whose radius is about $60 \%$ of the disk radius. Then, $T_{a w}$ exhibits quite an increase (about $3^{\circ} \mathrm{C}$ near the disk edge).

Since, for the tested conditions, $T_{w}-T_{\mathrm{aw}}$ is of the same order of magnitude as $T_{\mathrm{aw}}-T_{a}$, (8) explains the $T_{w}$ increase in Figure 4(b). It has to be pointed out that, in the case of much higher Joule heating, the effect of the $T_{\mathrm{aw}}$ would become less important and a monotonically decreasing wall temperature, towards the disk limb, would be observed. As Figure 5(b) shows, going from the disk centre to its periphery, the difference $T_{w}-T_{\mathrm{aw}}$ monotonically decreases because the corresponding convective heat transfer coefficient increases.

The use of $T_{\mathrm{aw}}$ allowed very accurate data for the Nusselt number dependence on the Reynolds number to be obtained and they are reported in Figure 6, where the laminar, transitional, and turbulent regimes are easily recognizable.

3.2. Rotating Disk with an Impinging Jet. The line scan facility of the Agema 900 infrared camera is exploited by Astarita and Cardone [9] who measure the convective heat transfer 


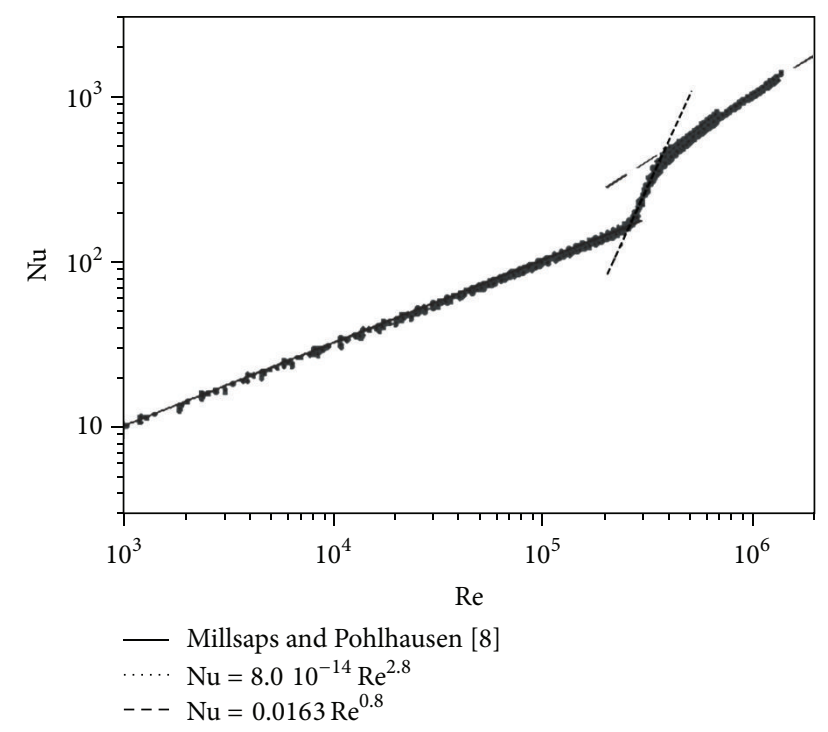

Figure 6: Nusselt number $\mathrm{Nu}$ versus Reynolds number Re for a rotating disk. From Cardone et al. [6].

coefficient on a rotating disk with a jet impinging at its centre. For each test, about 16,000 radial temperature profiles are acquired to reconstruct the main temperature profile and compute the Nusselt number profile azimuthal average. The authors use the same experimental apparatus described before (Figure 3) with the presence of the centred jet that is produced by air passing through a heat exchanger and a rotameter and finally exhausting from a nozzle. The heat exchanger ensures a jet bulk temperature practically equal $\left( \pm 0.1^{\circ} \mathrm{C}\right)$ to the temperature of the ambient air the jet mixes with to avoid mixing of two fluids (jet and ambient air) at different temperatures. Three nozzles with exit diameter $D$ from 4 to $8 \mathrm{~mm}$ are in turn used during the tests and the nozzle-exit-to-disk distance $z$ is varied between $3 D$ and $75 D$. The jet is always impinging perpendicularly at the disk centre.

In order to reduce the number of governing parameters and because of the lack of a theoretical analysis, it is essential to find a rational way to evaluate the relative importance of jet influence compared to that due to disk rotation. On the assumption that the heat transfer coefficient depends on the flow momentum rate, a reasonable dimensionless parameter is the ratio between the two momentum rates (one of the jet and the other one due to the disk rotation). By assuming a jet width proportional to the distance from the nozzle (the nozzle-to-disk distance should be relatively high as compared to $D$ ) and in the simplest case of laminar flow over the disk, such a parameter can be put in the form [9]

$$
\Phi=\frac{D V}{v}\left(\frac{v}{\omega z^{2}}\right)^{3 / 4}
$$

where $v$ and $\omega$ are the air kinematic viscosity coefficient and disk angular velocity, respectively.

Only convective heat transfer coefficients at the jet stagnation point $h_{o}$ are reported. By considering only the disk rotation (i.e., without jet), the flow is always laminar at the disk centre and $h_{o}$ can be evaluated from (9).

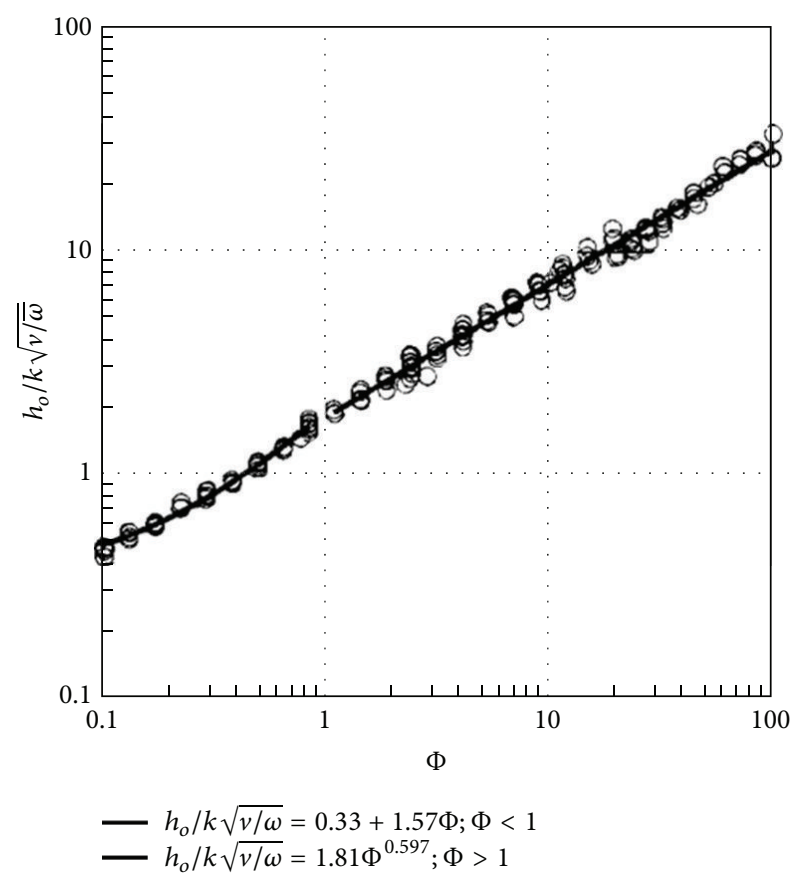

FIGURE 7: Convective heat transfer coefficient at the flow stagnation point of a jet perpendicularly impinging on the centre of a rotating disk. Adapted from Astarita and Cardone [9].

On the other hand, if one also considers the jet effect, the $h_{o}$ departure from the value predicted by (9) should be a function of $\Phi$ only. Therefore, the dimensionless quantity $\left(h_{o} / k\right) \sqrt{\nu / \omega}$ is plotted in Figure 7 as a function of $\Phi$, which refers to about 160 tests, carried out by randomly varying disk angular speed, nozzle diameter, jet flow rate, and nozzle-todisk distance $z$. Since $\Phi$ holds only for high values of the $z / D$ ratio, $z$ always fulfills the condition $z / D>14$. Data, for $\Phi>1$, appears well correlated, in the log-log plane, by a straight line, while the same is not true for smaller $\Phi$ values where a linear regression (11) shows a more satisfactory data fitting.

The two best correlation curves, which are also represented in Figure 7 with solid lines, are found to be

$$
\begin{aligned}
& \frac{h_{o}}{k} \sqrt{\frac{\nu}{\omega}}=0.33+1.57 \Phi ; \quad \text { for } \Phi<1, \\
& \frac{h_{o}}{k} \sqrt{\frac{\nu}{\omega}}=1.81 \Phi^{0.597} ; \quad \text { for } \Phi>1 .
\end{aligned}
$$

The two correlations (11) and (12) are obtained by using correspondingly a set of 42 and 122 data points and their square correlation factors turn out to be 0.988 and 0.989 , respectively. Equation (11) shows the initial linear dependence of $h_{o}$ on $\Phi$ and, for $\Phi \rightarrow 0$, clearly recovers (9).

3.3. $180^{\circ}$ Turn and Channels. As stated before, in order to cool a blade or vane, air from the HP compressor stage goes through the hub section into its interior and, after flowing through serpentine passages, is discharged into the main 


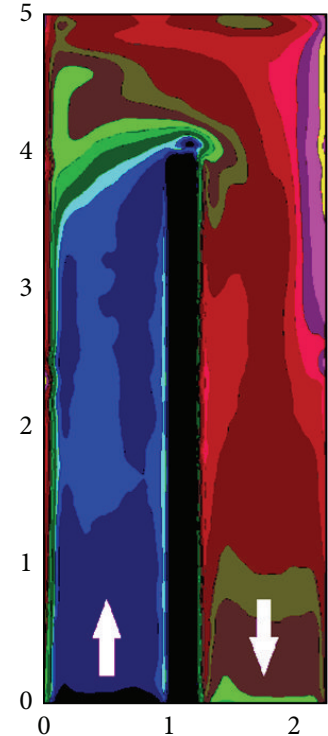

(a) $\operatorname{Re}=16000$

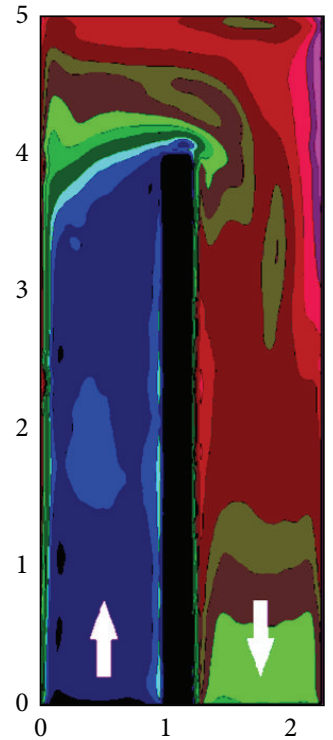

(b) $\operatorname{Re}=30000$

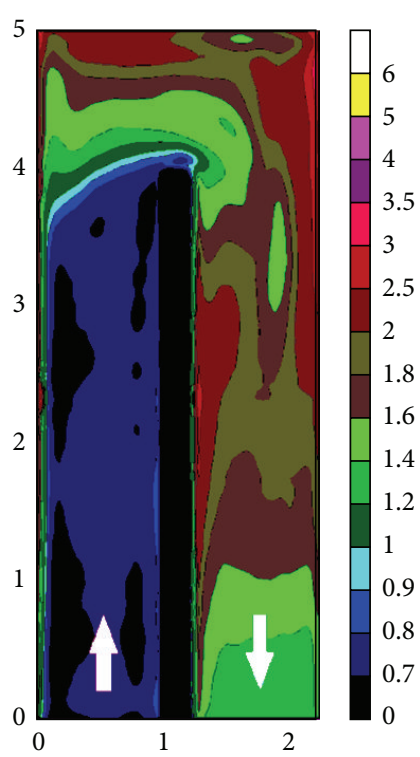

(c) $\operatorname{Re}=60000$

FIgure 8: Normalised Nusselt number $\mathrm{Nu} / \mathrm{Nu}^{*}$, distribution for the smooth channel. Adapted from Astarita and Cardone [10].

flow to provide film cooling as well. These passages are mostly made of several adjacent straight ducts, spanwise aligned along the blade and connected by $180^{\circ}$ turns (also called $U$ turns). Turns cause flow separation/reattachment and induce secondary flows so convective heat transfer coefficients exhibit high local variations with consequently increased wall thermal stresses.

By using a heated thin foil made of three joined printed circuit boards (each $600 \mathrm{~mm}$ long and total length $1800 \mathrm{~mm}$ ), Astarita and Cardone [10] obtain local heat transfer measurements in a $180^{\circ}$ sharp turn of a square channel (side, $D=80 \mathrm{~mm}$ ). The Reynolds number Re, based on the fluid bulk velocity and hydraulic diameter $D$, ranges from 16,000 to 60,000 and the ratio between $D$ and the thickness of the partition wall between the two adjacent ducts is equal to 5 . The quite large channel side is justified for two reasons, that is, to have a high data spatial resolution and to reduce the contribution of tangential conduction within the sensor. The reference temperature chosen for (8) is the local flow bulk temperature which is evaluated by measuring the inlet temperature and by making a one-dimensional energy balance along the channel, that is, along the channel main axis, with considered triangular heating sections in the turning zones.

Heat transfer coefficients are obtained from IR measurements and (8) for the channel heated from both sides and presented in terms of the normalised local Nusselt number $\mathrm{Nu} / \mathrm{Nu}^{*}$ (which can be considered also as $h / h^{*}$ ). $\mathrm{Nu}^{*}$ and $h^{*}$ are, respectively, the Nusselt number and the convective heat transfer coefficient values predicted by the Dittus and Bölter correlation for fully developed channel flows as interpreted by Kakac et al. [11]:

$$
\mathrm{Nu}^{*}=0.024 \mathrm{Re}^{0.8} \operatorname{Pr}^{0.4}
$$

Because of the low value of the pertinent Biot number (which, in the worst case, is appraised to be less than 0.01), the wall temperature is measured on the back side of the sensor where copper tracks are placed. Raw data is corrected for radiation, anisotropic tangential conduction [3], and natural convection at the back of the sensor, which is evaluated with an accurate calibration.

The normalised local Nusselt number distributions for three values of the Reynolds number Re are presented in Figure 8. The flow enters the duct from the left channel (inlet) and exits from the right one (outlet). In the inlet channel, the flow is quasifully/developed dynamically and thermally, so the heat transfer coefficient is slightly lower than that predicted by the Dittus and Bölter correlation. The flow field in the turn region, and downstream from it, appears to be highly three-dimensional and the Nu maps show zones with a relatively low heat transfer coefficient, corresponding to recirculation bubbles, as well as zones with high heat transfer coefficient, which are due to flow reattachment and/or to an increase in the flow's mean turbulence level, as well as flow impingement after turning.

A first recirculation bubble is located just before the first outer corner (upper left) and attached to the external wall. Two other regions with relatively low heat transfer coefficient may be noticed, the first near the tip of the partition wall and the second by the end wall at about the outlet channel axis. It is also possible to notice three high heat transfer zones: the first situated near the end wall; the second located below the second outer corner and extending for about 3 diameters; the third situated at about 2 diameters after the second inner corner and attached to the partition wall. They are due to the jet effect of the flow through the bend.

At the two higher Reynolds numbers (30,000 and 60,00), the Nusselt number distributions in the outlet channel and just after the turn show a region, about 1 diameter in length 


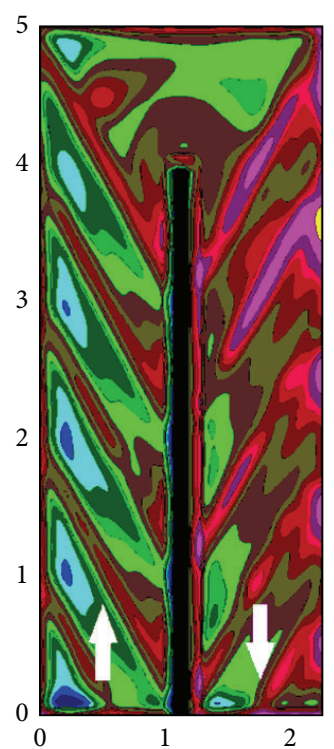

(a) $30^{\circ}$

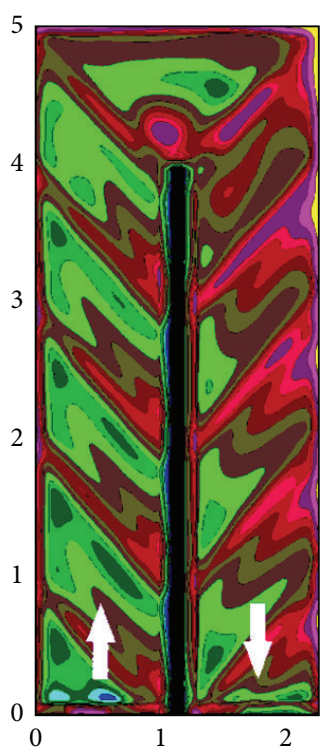

(b) $45^{\circ}$

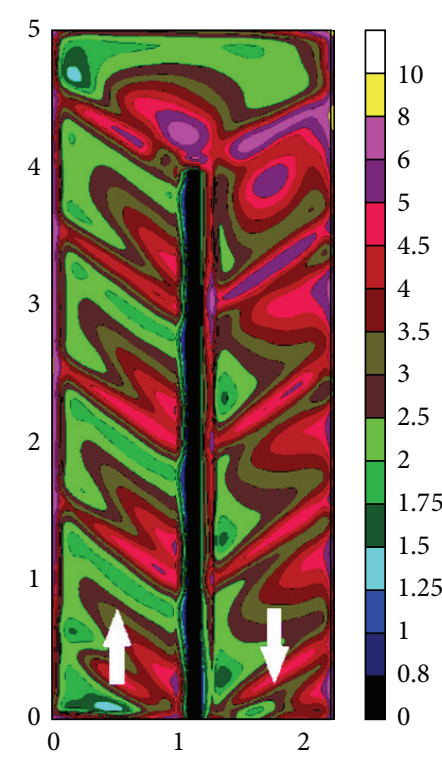

(c) $60^{\circ}$

FIGURE 9: $\mathrm{Nu} / \mathrm{Nu}^{*}$ distribution for a channel with superimposed ribs, $\mathrm{Re}=30,000$, symmetric heating, $p / e=10$, and various rib angles $\delta$; adapted from Astarita et al. [13].

and very slim, of relatively low local convective heat transfer. This is attributed by the authors to the formation, just after the turn, of four vortices, clearly shifted towards the external wall. However, the highest $\mathrm{Nu} / \mathrm{Nu}^{*}$ enhancement, which is present downstream of the second outer corner, occurs at the lowest Re because of the higher relative importance of the turbulence induced by the turn.

Rib turbulators, often attached to the blade heat exchanging walls, enhance the convective heat transfer efficiency and completely modify the channel flow field as well as the heat transfer distribution. With a single rib normal to the flow, the mainstream first separates, generating a recirculation zone ahead of the rib, and then reattaches over the rib itself. The further separation, occurring just after the rib, creates a second recirculation zone followed by another reattachment at the duct wall. If several ribs exist and their pitch is sufficiently large with respect to the rib height, these main flow features do not change and reoccur along the duct. Naturally, the presence of the ribs enhances the overall convective heat transfer coefficient both for the increased turbulent level they induce and for the effects associated with the reattachments.

For the channel described above, Carlomagno et al. [12], Astarita et al. [13, 14], and Astarita and Cardone [15] present detailed quantitative maps of the heat transfer distribution obtained with linear angled and V-shaped rib turbulators. Ribs are made of aluminium and have a square cross section $8 \mathrm{~mm}$ on a side (i.e., with a ratio between the duct side and rib height $D / e=10$ ), joined to the heat exchanging walls at an angle between $30^{\circ}$ and $60^{\circ}$ with respect to the duct axis. For reasons reported later, orthogonal ribs are less efficient and not tested. Two rib pitches $p$, two rib arrangements (superimposed or staggered), two heating conditions (from one or both channel sides), and three values of the Reynolds number, varying from 16,000 to 60,000 , are investigated, but only data relative to superimposed ribs and heating from both channel sides are herein reported. Raw data is corrected as indicated above.

The two-dimensional maps of the local normalised Nusselt number $\mathrm{Nu} / \mathrm{Nu}^{*}$, for the superimposed rib arrangement, $p / e=10$, symmetrical heating, and rib angle $\delta$ equal to either $30^{\circ}$ or $45^{\circ}$ or $60^{\circ}$ are shown in Figure 9 for $\operatorname{Re}=30,000$ [13]. In the normalised $\mathrm{Nu}$ maps, ribs are clearly visible due to the higher heat transfer rate occurring over them. Indeed, the higher value of the normalised Nusselt number over the ribs is a consequence of their higher effective heat transfer surface (i.e., fin effect) and of the flow reattachment there.

Owing to the high local thermal stresses which are difficult to avoid, there is a partial detachment of the ribs glued to the wall resulting in lower local $\mathrm{Nu} / \mathrm{Nu}^{*}$ value. For example, this effect is clear on both the last rib of the inlet duct and the first rib of the outlet duct, near the partition wall, for $\delta=45^{\circ}$ and $60^{\circ}$ (Figures 9(b) and 9(c)). The authors believe that this has a little influence on the local nearby data but highlight that the reported event is easily revealed by IR thermography. Upstream of the turn, the thermal pattern in the inlet duct appears to be recurring (a kind of thermally fully developed flow) except for some edge effects at duct entrance (which are found also at channel exit), linked to strong tangential conduction due to dissimilar nearby zones, there. The maps also show that the sharp turn already induces a slight change in the shape of the contour lines just before the last rib of the inlet duct.

The rib angle causes secondary flows under the form of two counterrotating vortices in the channel cross section; see also Figure 12 relative to a rotating channel, where, for the present case, the trailing wall has to be regarded as the external wall and the leading one as the partition wall. In 


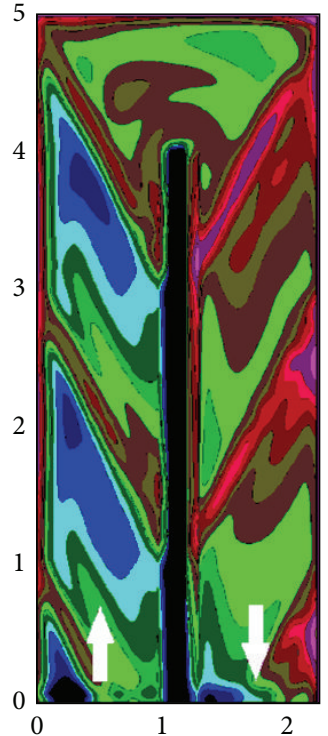

(a) $30^{\circ}$

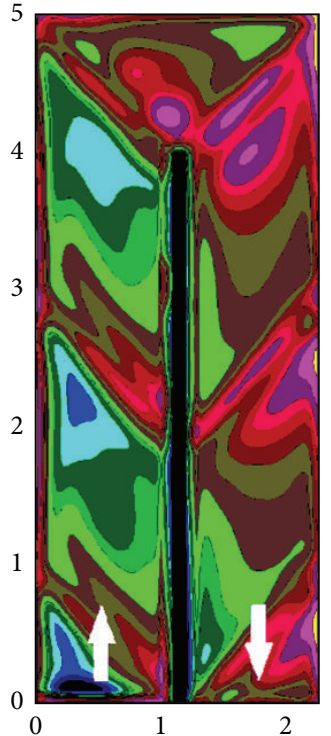

(b) $45^{\circ}$

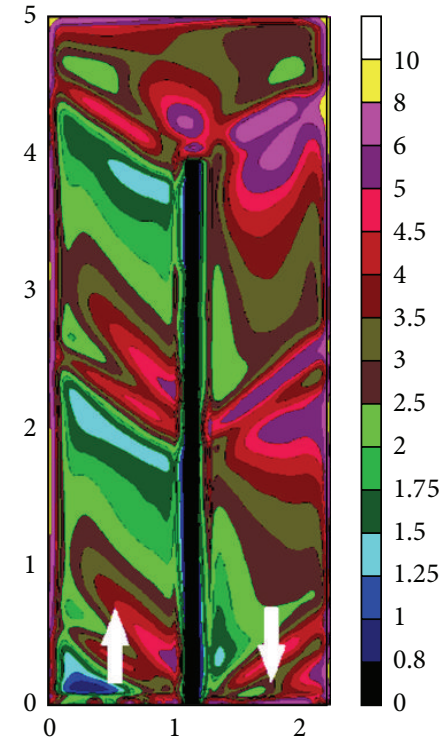

(c) $60^{\circ}$

FIGURE 10: $\mathrm{Nu} / \mathrm{Nu}^{*}$ distribution for a channel with superimposed ribs, $\mathrm{Re}=30,000, p / e=20$, and various rib angles $\delta$; adapted from Astarita et al. [13].

the inlet duct, the main flow nearby both the bottom and top walls, entrapped by the ribs, is accelerated towards the external wall (left side of the figure). The two secondary flows after licking this wall merge and go back, via the duct central zone, to the partition wall so as to practically generate a jet which impinges onto the latter. This explains the ribwise $\mathrm{Nu} / \mathrm{Nu}^{*}$ asymmetry. In fact, the jet presence tends to increase heat transfer near the partition wall with respect to that at the external one. So, colder fluid is pumped from the channel centre towards the heat exchanging walls. By increasing $\delta$, both the asymmetry of Nusselt number distribution and the averaged $\mathrm{Nu} / \mathrm{Nu}^{*}$ value become more evident, due to the increased strength of the secondary flows. Naturally, the latter ones do not exist for ribs normal to the channel axis. The maps show also that, towards channel exit, secondary flows (that are reversed) enhance heat transfer near the external wall (right side of the figure) with respect to that near the partition wall.

In the inlet duct, the reattachment downstream of the ribs can be identified as the locus of the normalised Nusselt number local maxima when moving in streamwise direction. The increase of reattachment distance by moving towards the external wall is most likely due to the interaction of the main flow with the secondary one. For the lowest $\delta$ value, going towards the left wall of the inlet channel, the reattachment line between ribs appears to vanish and a relatively large low heat transfer zone completely fills the wall leftmost part. Most probably towards the channel left side, owing to the relatively small distance between two successive ribs, the main flow, interacting with the secondary one, is not able to reattach in the zone between them so that it reattaches directly over the top of the following rib. The separation zone after each rib is strongly influenced by the secondary flow impingement towards the partition wall. On the other hand, the separation zone ahead of each rib remains clearly visible and it is not much affected by the secondary flow, its width remaining practically constant along the rib. The separation zone after each rib, which should be confined between the rib and the reattachment line, has an indeterminate shape because of the asymmetry of the normalised Nusselt number contours. Towards the right wall, the reattachment line is very close to the preceding rib; thus the separation zone is small; moving towards the left wall, its size increases and for $\delta=30^{\circ}$, as already mentioned, tends to occupy the whole zone between ribs. For $\delta=60^{\circ}$, the separation zone ahead of each rib is quite clearly visible and does not appear to be strongly influenced by the secondary flow while, for $\delta=45^{\circ}$, it splits in two different low $\mathrm{Nu} / \mathrm{Nu}^{*}$ zones, becoming practically indistinguishable for $\delta=30^{\circ}$.

In the turn, the low heat transfer zone attached to the external wall just before the first outer corner, already seen at the smooth channel, is again visible for $\delta=30^{\circ}$ and $\delta=60^{\circ}$, while, for $\delta=45^{\circ}$, the rib presence does not allow its formation. For $\delta=30^{\circ}$, the interaction between the secondary flow and the sharp turn produces two high heat transfer zones and, between them, a local minimum just after the last rib, while, for the two larger angles, only one high heat transfer zone is found near the partition wall. At the outlet channel exit, the recurring flow is not completely recovered and the normalised Nusselt number mean values are yet larger compared to those in the inlet channel.

By increasing the rib pitch $(p / e=20)$, the Nusselt number distributions presented in Figure 10 are found. Because of the absence of some ribs in the channel, the secondary flow has a less important effect on the spanwise distribution of the heat transfer coefficient, but the previously discussed main features of the flow are substantially retained.

In the inlet duct downstream of the ribs, the reattachment line shows itself to be moved slightly forward compared to 


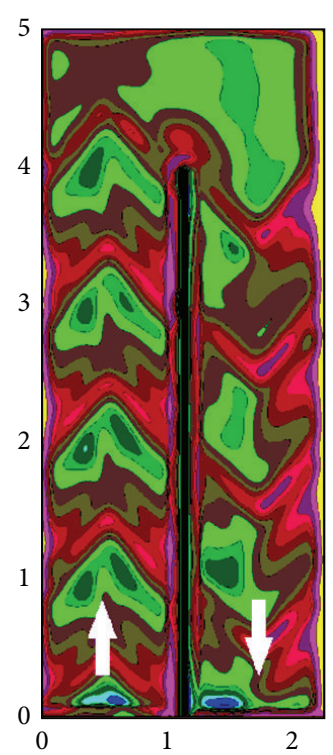

(a) VPP

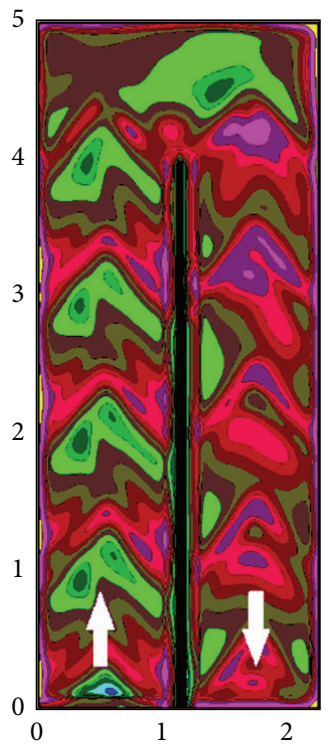

(b) VPN

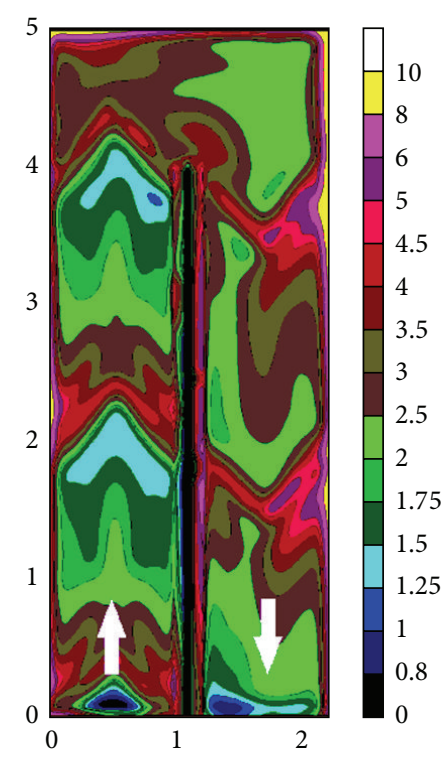

(c) VPP

FIGURE 11: $\mathrm{Nu} / \mathrm{Nu}^{*}$ distribution for a channel with superimposed ribs, $\mathrm{Re}=30,000$ : (a) VPP, $p / e=10$; (b) VPN, $p / e=10 ;(\mathrm{c}) \mathrm{VPP}, p / e=20$; adapted from Astarita et al. [14].

previous case, although in this configuration too the reattachment distance increases moving towards the external wall. For $\delta=30^{\circ}$, the reattachment line does not disappear towards the external wall, as found for $p / e=10$. The separation zone after the ribs again seems more evident towards the left wall, where a well-defined low heat transfer zone is found. The development of the boundary layer after the reattachment is shown by the downstream decrease of the normalised Nusselt number.

For the two smaller angles, the separation zone ahead of each rib is not easily identified but, towards the left wall, a triangular low heat transfer zone appears, while, for $\delta=60^{\circ}$, again an easily detectable separation zone is found.

In the turn zone and outlet channel, the distribution of the normalised Nusselt number, already found for the smaller pitch, is confirmed even if some differences are present and the mean value decreases.

Typical normalised Nusselt number distributions for the $\mathrm{V}$-shaped rib configurations are presented in Figure 11. As it is evident from the $\mathrm{Nu} / \mathrm{Nu}^{*}$ maps, ribs have a $\mathrm{V}$ shape (with an angle of $45^{\circ}$ with respect to the duct axis), their apex always pointing downstream for the VPP configuration (Figures 11(a) and 11(c)), while, only in the outlet duct, for the VPN configuration (Figure 11(b)), the ribs point upstream. For the VPP configuration, two rib pitches are shown in the figure.

In these cases, the secondary flows due to the V-shaped ribs have the form of two pairs of counterrotating cells, which, in the inlet channel for all configurations, produce variations in the spanwise Nusselt number distribution by decreasing heat transfer near the channel axis compared to that towards the side walls. In the outlet channel, the same occurs for the VPP rib configuration while, for the VPN one, the behaviour is obviously reversed.
Again, especially in the inlet duct, the reattachment line downstream of the ribs can be identified by the locus of the normalised Nusselt number local maxima. The reattachment distance, which increases for the higher rib pitch, also appears to increase going from the walls towards the channel axis and this is most likely due to the interaction of the main flow with the secondary ones.

In the proximity of the first external corner, it is possible to notice a low heat transfer zone, due to a recirculation bubble as already observed for the previous configurations. Just after the last rib near the partition wall, the interaction between the secondary flow and the sharp turn produces a high heat transfer zone that tends to shift downstream with increasing pitch. For the VPN configuration, the presence of the rib in the turn zone reduces the zone of relatively low convective heat transfer.

3.4. Rotating Channels. The rotation of a channel gives rise to Coriolis forces in the flow and enhances buoyancy forces, which both completely change the flow and the local heat transfer coefficient distribution, as described previously for a static channel. As schematically indicated in Figure 12 [16], in a rotating channel, it is usual to call the wall that goes ahead leading and the one that follows trailing.

For a radially outward flow, the Coriolis force produces a secondary flow, in the plane perpendicular to the main flow direction, in the form of a pair of counterrotating vortices. The sketch of Figure 12 shows that the secondary flow pushes the fluid particle in the centre of the channel towards the trailing wall, then along the sidewalls, and finally to the leading wall. As regards the static case, these secondary flows enhance heat transfer at the trailing wall compared to that at the leading wall. When the flow is reversed, that is, radially 


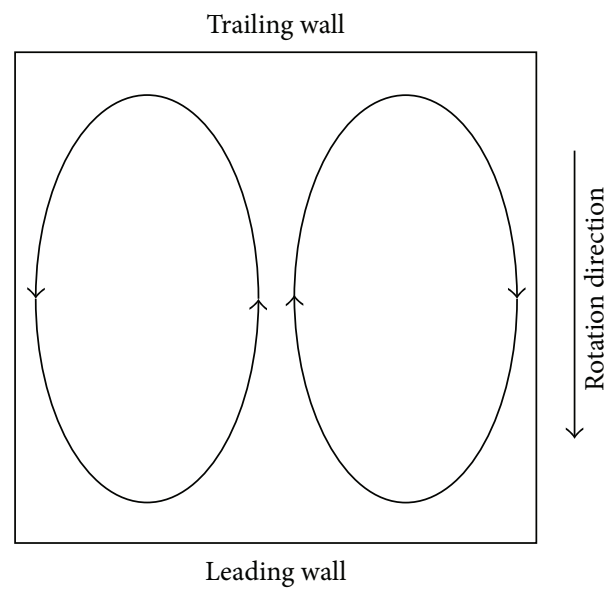

FIGURE 12: Secondary flows in a rotating channel with radially outward flow; adapted from Gallo et al. [16].

inward flow, one has only to change the role played by the leading wall for that of the trailing one and vice versa.

Furthermore, since heat exchange at the wall causes a density difference between the fluid core and that near the wall, the strong centripetal acceleration, which may occur due to rotation, gives rise to a radial buoyant effect. This magnifies the influence of the Coriolis force in the radially outward flow and reduces it (or changes its sign) in the opposite case. Therefore, the velocity gradient at the wall changes and, consequently, the heat transfer coefficient also modifies.

One of the first attempts to measure convective heat transfer coefficients in a rotating air channel with IR thermography is reported by Cardone et al. [17]. The utilized apparatus is a direct consequence of the used heated thin foil sensor. Since the sensor's back surface (which is to be viewed by the IR camera) cannot be thermally insulated, the only way to prevent high external thermal losses by forced convection over this surface is to have the channel rotating in a vacuum chamber. Really, for turbulent flow, the convective heat transfer coefficient from a rotating channel to the ambient fluid is also proportional (with an exponent smaller than unity) to the ambient fluid density. Therefore, a strong reduction of the ambient pressure causes a decrease of the fluid density and, consequently, of the external convective heat transfer coefficient.

The apparatus, represented in Figure 13, consists of a confinement circular chamber (vacuum tank) which contains an arm mounted on a rotating shaft. The tank is $750 \mathrm{~mm}$ in diameter and its structure and seals are designed so as to have the tank operating at an absolute pressure below $100 \mathrm{~Pa}$. The rotating arm includes a two-pass square channel, with side of $22 \mathrm{~mm}$ and length of $330 \mathrm{~mm}$, which is balanced by a counterweight and fed through the hollow shaft which also provides the air exhaust. To reduce the rotating mass as well as the wall thermal conductance, the walls of the two-pass channel are made of composite material (about $1 \mathrm{~mm}$ thick): epoxy resin and Kevlar mat. The thickness of the channel frontal cover, which also constitutes the heated thin foil heat flux sensor, is chosen so as to maintain the deformation

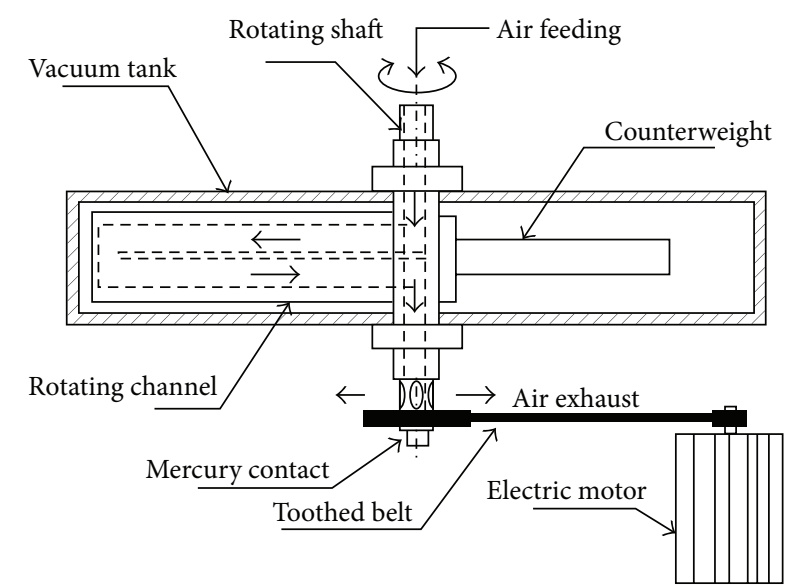

FIgURE 13: Experimental apparatus for a rotating channel of Cardone et al. [17].

(under the effect of the pressure difference between the inside of the channel and the vacuum tank) at less than $0.1 \mathrm{~mm}$. A printed circuit board is used to generate the uniform heating prescribed by the chosen heat flux sensor and it is connected to a stabilized DC power supply via a mercury rotating contact attached to the shaft.

At the time of testing, practically all of the IR cameras commercially available were based on a single thermal detector with an optical scanning mechanism so that the complete frame acquisition frequency was relatively low. Since the channel rotates during the tests and since the frame acquisition frequency of the used infrared system was $15 \mathrm{~Hz}$, it was not possible to take the whole thermal picture in one single shot. For example, at 2,000 rpm, during the time needed for the acquisition of a full frame, the channel would make more than two revolutions around its axis of rotation. To solve this problem, Cardone et al. [17] used the line scan facility of the AGEMA 900 infrared system to take advantage of the much higher acquisition frequency of a line $(2,551 \mathrm{~Hz})$. Therefore, adhoc software was developed to reconstruct an averaged (in time) image from multiple line scan acquisitions.

Details of this procedure can be found in the Ph.D. degree thesis by Astarita [18]. In this pioneering work, the spatial resolution of the results turned out to be relatively poor on account of the strong influence of the tangential conduction heat fluxes which are due to the small dimension of the channel $\left(22 \times 22 \mathrm{~mm}^{2}\right)$. Therefore, the measured results were not the detailed ones that can be obtained with IR thermography, but this work is reported because it offers a useful option in order to study flows into moving bodies with IR thermography.

A different approach, in order to reduce the relative importance of the external convection with respect to the internal one, was chosen by Gallo et al. [16] to obtain more detailed convective heat transfer coefficient $h$ maps near a $180^{\circ}$ sharp turn of a rotating $U$ channel with the heated thin foil sensor. The authors decided to significantly increase $h$ at the sensor's front surface by using water as a working fluid as well as to use a much larger channel in order to reduce 


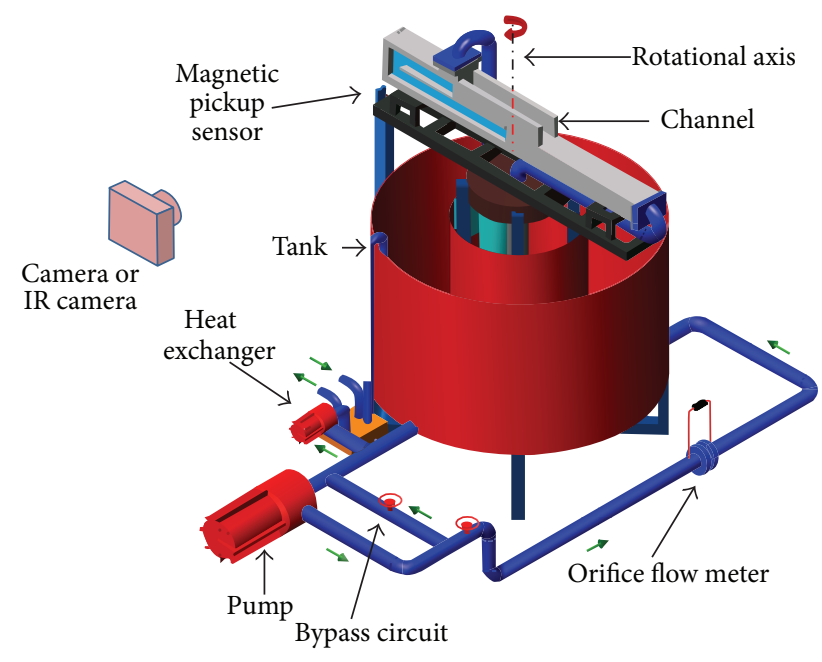

FIGURE 14: Experimental apparatus for a rotating channel of Gallo et al. [16].

its rotational speed and, therefore, $q_{l}$ at the back surface. In this way, they were able to obtain quite a good spatial resolution and low tangential conduction in the acquired measurements.

The experimental apparatus, represented in Figure 14, consists of a Perspex two-pass water channel with a sharp $180^{\circ}$ turn, mounted on a revolving platform whose rotational speed $\omega$ can be continuously varied and precisely monitored in the range of $0 \div 60 \mathrm{rpm}$. The channel has a square cross section of $60 \mathrm{~mm}$ on a side and length of $1200 \mathrm{~mm}$ ahead of the $180^{\circ}$, which provides a hydro-/thermodynamically fully developed flow before the turn. The central partition wall dividing two adjacent ducts is $12 \mathrm{~mm}$ thick. Water from a tank is pumped through an orifice meter and a rotating hydraulic coupling and, after flowing in the test channel, is discharged back into the tank. Mass flow rate can be varied with a bypass circuit and the inlet to channel water temperature is kept constant with a heat exchanger. A magnetic pick-up allows the synchronization of the IR image acquisition.

The apparatus is capable of simulating both Reynolds number Re and Rotation number Ro $=\omega D / V$ (where $\omega$ is the angular speed of the channel) values typical of turbine blades. The $D$ increase and the $V$ decrease (to maintain a given $\mathrm{Re}$ ) allow a drastic reduction in $\omega$ by keeping a constant Ro. Results relative to the static channel (no rotation) well agree with the measurements performed with air by Astarita and Cardone [10], already presented in Figure 8.

In Figure 15(a), the normalised Nusselt number $\mathrm{Nu} / \mathrm{Nu}^{*}$ (as earlier defined) distribution over the leading wall, for $\operatorname{Re}=20,000$ and Ro equal to 0.3 , is represented. In the inlet duct, the flow appears to be fully developed, also from the thermal point of view, since the normalised Nusselt number is practically constant. The $\mathrm{Nu} / \mathrm{Nu}^{*}$ values are lower than those relative to the static case and, following Gallo et al. [16], decrease with the increasing of the rotation number.

In the first half of the first corner, it is possible to notice a high heat transfer zone that is caused by the inversion of the Coriolis force in the turn zone. Really, in the turn zone, the radial velocity component suddenly decreases and changes sign with a consequent decrease and inversion of the Coriolis force. This inversion makes the flow separate on the trailing side and abruptly reattach towards the leading one, with a strong increase of the normalised Nusselt number at the reattachment point. Other low and high heat transfer zones are clearly visible in the normalised Nusselt number map and their cause is explained in detail by flow field measurements made with particle image velocimetry in the work of Gallo et al. [19].

As it is possible to see from Figure 15(b), the normalised Nusselt number distribution over the trailing wall appears to be completely different from that on the leading wall. In the inlet channel, the $\mathrm{Nu} / \mathrm{Nu}^{*}$ values are again uniform but much higher than those for the static case and for the leading wall; besides, as reported by Gallo et al. [16], they tend to increase for increasing rotation number Ro.

In the turn region, it is possible to note that the isoNusselt number zone tends to advance into the first corner of the turn and to insinuate in the first half of the second corner. On the second outer corner, it is possible to note a high heat transfer zone that, near the frontal wall, results as being adjacent to a relatively lower heat transfer zone. In the outlet duct, the Nusselt number distribution relative to the trailing wall exhibits two high heat transfer coefficient zones located on the centre and downstream near the partition wall, respectively. Again, the reason for such behaviour can be found in the paper by Gallo et al. [19].

It should be noted that the measurements by Gallo et al. [16] are performed at relatively high Biot number because of the presence of water in the channel and that the heated tracks of the printed circuit are placed on the sensor's back surface for electrical insulation reasons. Therefore, data are reduced according to a special procedure.

3.5. Spray Tubes. Sometimes, to cool leading edges of turbine vanes, a spray tube inside and parallel to them (in aeronautics sometimes called piccolo tube), with an array of aligned holes, generates a row of jets which blow cold air to maintain the blade surface temperature below critical values [21]. Piccolo tubes are also amongst the most widely used anti-icing devices for wings and engine nacelles of commercial aircraft [22]. In such devices, hot air is extracted from the compressor and blown on the inner surface of the leading edge through small holes drilled in a pipe. The aim is to supply enough energy to keep the surface at a temperature above the freezing point of water and to liquefy impinging ice crystals. In these devices, the impingement distance is relatively short, this problem being addressed for single jets by Carlomagno and Ianiro [23].

A piccolo tube is experimentally analysed by Imbriale et al. [20]. The test article includes the leading edge of a NACA 0012 wing profile with $1.50 \mathrm{~m}$ chord $c$, with a spray tube located inside at $4 \%$ of the chord profile. The profile is $0.20 \mathrm{~m}$ spanwise long and it is stopped at about $1 / 10$ of the chord with an open side to facilitate discharge of injected gas so as to avoid recirculation effects. To allow measurements with the heated thin foil sensor, the leading edge section consists 


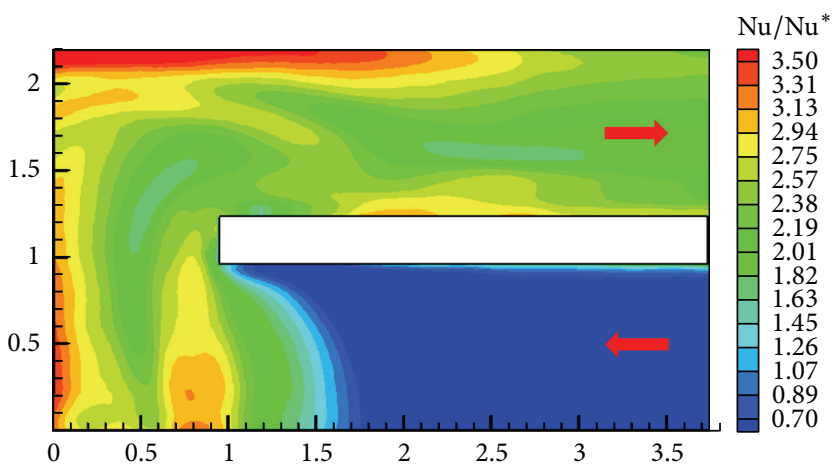

(a)

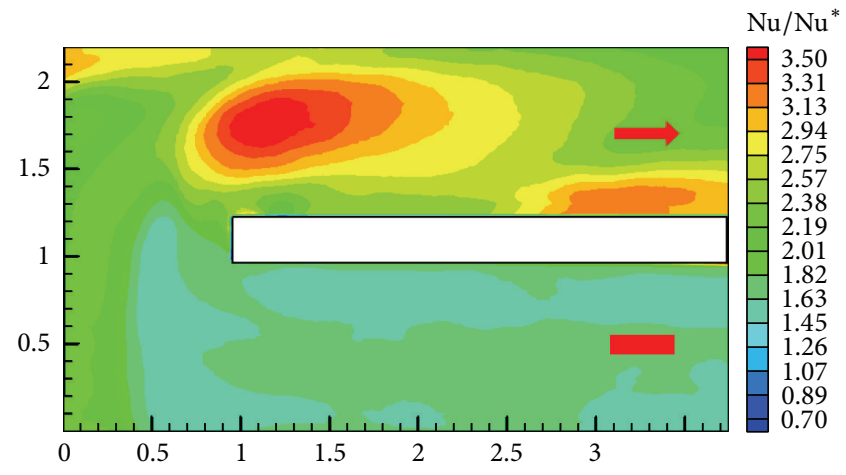

(b)

Figure 15: Normalised Nusselt number $\mathrm{Nu} / \mathrm{Nu}^{*}$ distributions for a smooth rotating channel: (a) leading wall and (b) trailing wall; adapted from Gallo et al. [19].

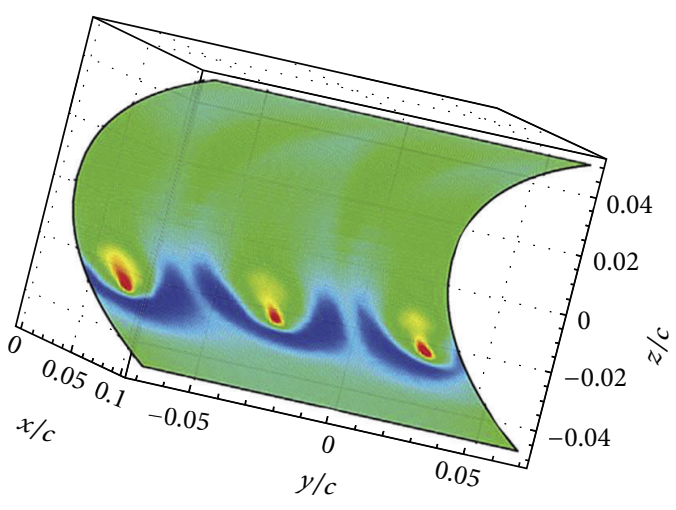

(a)

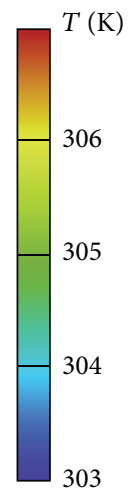

303

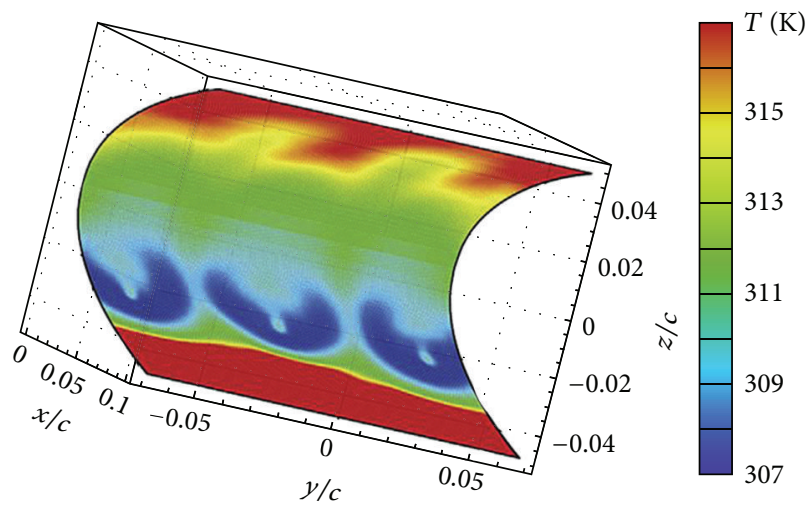

(b)

FIGURE 16: 3D temperature reconstruction for $d=4 \mathrm{~mm}, \phi=30^{\circ}, M=1.0$, and $p / d=15$ : (a) adiabatic wall temperature (foil not heated) and (b) wall temperature (heated foil); adapted from Imbriale et al. [20].

of a thin stainless steel sheet ( $40 \mu \mathrm{m}$ thick) lodged inside an ad hoc fixture. In particular, different spray tubes are used with a different number of holes from 3 to 5 , orifice diameter $D$ from $2 \mathrm{~mm}$ to $4 \mathrm{~mm}$, and holes pitch-to-diameter ratio $p / D$ between 5 and 15 . In addition, the jet inclination $\phi$ with respect to airfoil chord is varied from $0^{\circ}$ to $50^{\circ}$ by rotating the spray tube around its axis. The exit Mach number $M$ is varied from 0.6 to 1.0 and the Reynolds number $(\operatorname{Re}=V D / \nu)$ is based on the ideal jet exit velocity $V$. In order to avoid measurement errors due to the surface directional emissivity decay, the camera viewing angle is kept lower than $55^{\circ}$. Raw data is corrected for radiation, tangential conduction within the sensor, and natural convection at the foil viewed side.

Due to the curvature of the viewed surface, to obtain the temperature distribution over the entire leading edge surface, at least two images must be acquired; temperature maps are reconstructed on the object mesh grid according to Cardone et al. [24]. This involves not only a different data reduction, but primarily a geometrical calibration of the IR camera. Then, before performing calculation with (8), the temperature maps of $T_{w}$ and $T_{\mathrm{aw}}$ have to be reconstructed on a $3 \mathrm{D}$ mesh grid from the $2 \mathrm{D}$ IR images.
An example of such a map reconstruction is presented in Figure 16 for the adiabatic wall temperature $T_{\mathrm{aw}}$ (Figure 16(a), foil not heated) and for the wall temperature $T_{w}$ (Figure 16(b), heated foil), taken for three aligned holes, $d=4 \mathrm{~mm}$, inclination angle $\phi=30^{\circ}, M=1.0$, and orifice pitchto-diameter ratio $p / d=15$. Maps clearly exhibit the jet impingement zones which are not centred with respect to the chord due to the $30^{\circ}$ jet inclination and, again, the influence of the relatively high Mach number on the adiabatic wall temperature distribution is recognized.

A typical heat transfer $(\mathrm{Nu})$ distribution, for the same testing conditions of Figure 16, is shown in Figure 17. The impinging jets entail very high Nusselt number values with local peaks in a small region matching with the jets centres; so, these peaks clearly locate the area of jet impingement on the front-side surface. Even though the holes are perfectly circular, the high Nu region somehow stretches in a chordwise direction. This behaviour is due to the jets' inclination with respect to the foil surface. In fact, only jets with inclination $\phi$ equal to either $0^{\circ}$ or $65^{\circ}$ are perpendicular to the foil; for other $\phi$ values, the impingement is affected by inclination effects. 


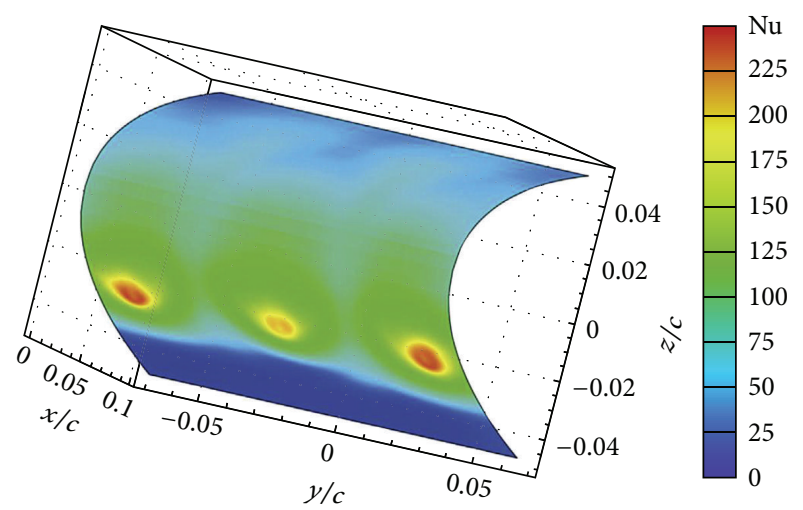

FIgURE 17: Nusselt number reconstruction for $d=4 \mathrm{~mm}, \phi=30^{\circ}$, $M=1.0$, and $p / d=15$; adapted from Imbriale et al. [20].

In addition, variations of the Nusselt number distribution are present at the upper back region $(z / c>0.2)$. In particular, it is possible to recognize local $\mathrm{Nu}$ increase in the spanwise direction between two contiguous jets, at the same locations where the two green streaks are visible in the wall temperature map of Figure 16(b). This behaviour resembles the fountain effect, already described in literature [25]. However, some fundamental differences regarding position and appearance of such local maxima exist. In fact, the fountain effect, described in literature, is exactly localized between contiguous jets, while, in the present case, local heat transfer maxima seem to originate between jets but they extend and strengthen on the backside region, far from the impingement.

\section{Conclusions}

The heated-thin-foil technique, associated with the detection of surface temperature by means of infrared thermography, is used to measure the convective heat transfer coefficient in several fluid flow configurations which are relevant to the cooling of gas turbine components, namely, a rotating disk with, or without, a centred impinging jet; the flow in a twopass smooth (with, or without, rotation), or ribbed, channel with a $180^{\circ}$ sharp turn; a spray tube placed inside the leading edge of a turbine blade.

For all the applications shown, the infrared technique adopted has proved its capability to accurately measure the convective heat transfer coefficient distributions in the fluid flows generated by the examined complex geometries and to be a very effective investigation tool for thermo-fluiddynamic experimental research.

When compared to standard techniques, the use of an infrared camera as a temperature transducer in convective heat transfer measurements appears advantageous from several points of view. In fact, since the IR camera is fully two-dimensional (nowadays, up to more than $1 \mathrm{M}$ pixels per frame), besides producing a whole temperature map, it allows an easier evaluation of errors due to radiation and tangential conduction. Furthermore, the camera is nonintrusive (i.e., it does not disturb the measuring process and allows avoiding conduction through thermocouple or RTD wires). It also has high sensitivity (down to $10 \mathrm{mK}$ ) and low response time (down to $20 \mathrm{~ms}$ ). As such, IR thermography can be effectively exploited to measure convective heat fluxes even in circumstances where they undergo drastic variations.

Finally, it has to be pointed out that the concurrent use of infrared thermography with the particle image velocimetry (PIV) technique is of great help in the understanding of a thermo-fluid-dynamic phenomenon, especially when exploiting tomographic PIV [23].

The potential of tomographic PIV already allows for quite detailed inspection and characterization of flow physics. In fact, time resolved tomographic PIV has been already applied to water jets [26] and some technical developments may also permit relatively inexpensive exploitation of instrumentation [27]. At the same time, the application of high speed measurements to air flows is limited by the laser power and speed, even if solutions for high speed volumetric measurements in air have been proposed and are being improved [28]. However, it has to be pointed out that tomographic PIV is far from having reached its final development and assessment stage. Researchers are working on the enhancement of spatial resolution and measurement accuracy [29] which could undoubtedly also produce further comprehensive benchmarks for computational methods. Some thermographic measurements, concurrently performed with standard PIV, have already appeared in [19].

\section{Symbols}

\section{Roman Letters}

a: Constant (9)

c: Airfoil chord

$c_{p}$ : Fluid specific heat at constant pressure

$C_{1}$ : First radiation constant

$C_{2}$ : Second radiation constant

D: Channel side, Nozzle diameter

$e$ : Rib height

$E_{b}$ : Emissive power of black body

I: Spectral emissive power

$h$ : Convective heat transfer coefficient

$k$ : Fluid thermal conductivity coefficient

$p$ : Pitch

$q$ : Heat flux

$r$ : Radial coordinate

$s$ : Sensor thickness

T: Temperature

$V$ : Fluid velocity

$x$ : Coordinate

$y$ : Coordinate

$z$ : Coordinate, Nozzle-to-plate distance.

\section{Greek Letters}
$\alpha_{r}:$ Absorptivity coefficient
$\delta$ : Rib Angle
$\varepsilon$ : Emissivity coefficient 
$\Phi:$ Dimensionless parameter (10)

$\lambda$ : Wavelength of electromagnetic wave

$\nu$ : Fluid kinematic viscosity coefficient

$\rho_{r}$ : Reflectivity coefficient

$\sigma$ : Stefan-Boltzmann constant

$\tau_{r}$ : Transmissivity coefficient

$\phi$ : Jet inclination to airfoil chord

$\omega$ : Angular speed.

\section{Subscripts}

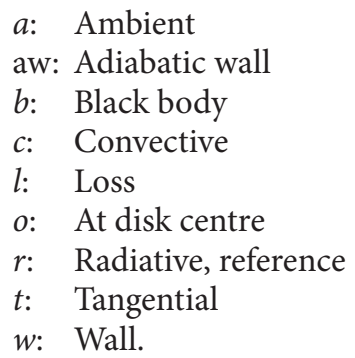

Apices

$m$ : At maximum emissive power

*: As per Dittus and Bölter correlation.

\section{Dimensionless Groups}

Bi: Biot number, $h s / k_{s}$

$M$ : Mach number

$\mathrm{Nu}$ : Nusselt number, $h D / k$

$\mathrm{Nu}_{r}$ : Local Nusselt number on the disk, $h r / k$

Pr: Prandtl number, $c_{p} \mu / k$

Re: Reynolds number, $V D / v$

Re: Local Reynolds number on the disk, $V r / \nu$

Ro: Rotational number, $\omega D / V$.

\section{Conflict of Interests}

The authors declare that there is no conflict of interests regarding the publication of this paper.

\section{References}

[1] K. G. Kyprianidis, "Future aero engine designs: an evolving vision," in Advances in Gas Turbine Technology, E. Benini, Ed., chapter 1, pp. 3-24, InTech, Rijeka, Croatia, 2011.

[2] T. Astarita, G. Cardone, and G. M. Carlomagno, "On the cooling of gas turbines," Journal of Flow Visualization and Image Processing, vol. 8, no. 2-3, pp. 287-302, 2001.

[3] T. Astarita and G. M. Carlomagno, Infrared Thermography for Thermo-Fluid-Dynamics, Springer, Berlin, Germany, 2013.

[4] G. Carlomagno, L. de Luca, G. Cardone, and T. Astarita, "Heat flux sensors for infrared thermography in convective heat transfer," Sensors, vol. 14, no. 11, pp. 21065-21116, 2014.
[5] G. Cardone, T. Astarita, and G. M. Carlomagno, "Infrared heat transfer measurements on a rotating disk," Optical Diagnostics in Engineering, vol. 1, pp. 1-7, 1996.

[6] G. Cardone, T. Astarita, and G. M. Carlomagno, "Heat transfer measurements on a rotating disk," International Journal of Rotating Machinery, vol. 3, no. 1, pp. 1-9, 1997.

[7] T. Astarita, G. Cardone, and G. M. Carlomagno, "Spiral vortices detection on a rotating disk," in Proceedings of the 23rd Congress of the International Council of the Aeronautical Sciences (ICAS '02), Paper no. ICAS2002-3.6.4, 2002.

[8] K. Millsaps and K. Pohlhausen, "Heat transfer by laminar flow from a rotating-plate," Journal of the Aeronautical Sciences, vol. 19, pp. 120-126, 1952.

[9] T. Astarita and G. Cardone, "Convective heat transfer on a rotating disk with a centred impinging round jet," International Journal of Heat and Mass Transfer, vol. 51, no. 7-8, pp. 1562-1572, 2008.

[10] T. Astarita and G. Cardone, "Thermofluidynamic analysis of the flow in a sharp $180^{\circ}$ turn channel," Experimental Thermal and Fluid Science, vol. 20, no. 3-4, pp. 188-200, 2000.

[11] S. Kakac, R. K. Shah, and W. Aung, Handbook of Single Phase Flow Convective Heat Transfer, Wiley, New York, NY, USA, 1987.

[12] G. M. Carlomagno, T. Astarita, and G. Cardone, "Convective heat transfer and infrared thermography," Annals of the New York Academy of Sciences, vol. 972, pp. 177-186, 2002.

[13] T. Astarita, G. Cardone, and G. M. Carlomagno, "Convective heat transfer in ribbed channels with a $180^{\circ}$ turn," Experiments in Fluids, vol. 33, no. 1, pp. 90-100, 2002.

[14] T. Astarita, G. Cardone, and G. M. Carlomagno, "Infrared thermography: an optical method in heat transfer and fluid flow visualisation," Optics and Lasers in Engineering, vol. 44, no. 3-4, pp. 261-281, 2006.

[15] T. Astarita and G. Cardone, "Convective heat transfer in a square channel with angled ribs on two opposite walls," Experiments in Fluids, vol. 34, no. 5, pp. 625-634, 2003.

[16] M. Gallo, T. Astarita, and G. M. Carlomagno, "Heat transfer measurements in a rotating two-pass square channel," Quantitative InfraRed Thermography Journal, vol. 4, no. 1, pp. 41-62, 2007.

[17] G. Cardone, T. Astarita, and G. M. Carlomagno, "Wall heat transfer in static and rotating $180^{\circ}$ turn channels by quantitative infrared thermography," Revue Générale de Thermique, vol. 37, no. 8, pp. 644-652, 1998.

[18] T. Astarita, Alcuni aspetti di scambio termico nelle turbine a gas [Ph.D. thesis], Universita di Napoli, Naples, Italy, 1996, (Italian).

[19] M. Gallo, T. Astarita, and G. M. Carlomagno, "Thermo-fluiddynamic analysis of the flow in a rotating channel with a sharp 'u' turn," Experiments in Fluids, vol. 53, no. 1, pp. 201-219, 2012.

[20] M. Imbriale, A. Ianiro, C. Meola, and G. Cardone, "Convective heat transfer by a row of jets impinging on a concave surface," International Journal of Thermal Sciences, vol. 75, pp. 153-163, 2014.

[21] H. Iacovides and B. E. Launder, "Internal blade cooling: the Cinderella of computational and experimental fluid dynamics research in gas turbines," Proceedings of the Institution of Mechanical Engineers, Part A: Journal of Power and Energy, vol. 221, no. 3, pp. 265-290, 2007.

[22] T. Cebeci and F. Kafyeke, "Aircraft icing," Annual Review of Fluid Mechanics, vol. 35, pp. 11-21, 2003.

[23] G. M. Carlomagno and A. Ianiro, "Thermo-fluid-dynamics of submerged jets impinging at short nozzle-to-plate distance: 
a review," Experimental Thermal and Fluid Science, vol. 58, pp. 15-35, 2014.

[24] G. Cardone, A. Ianiro, G. dello Ioio, and A. Passaro, "Temperature maps measurements on 3D surfaces with infrared thermography," Experiments in Fluids, vol. 52, no. 2, pp. 375385, 2012.

[25] H. Iacovides, D. Kounadis, B. E. Launder, J. Li, and Z. Xu, "Experimental study of the flow and thermal development of a row cooling jets impinging on a rotating concave surface," Journal of Turbomachinery, Transactions of ASME, vol. 127, no. 1, pp. 222-229, 2005.

[26] D. Violato, A. Ianiro, G. Cardone, and F. Scarano, "Threedimensional vortex dynamics and convective heat transfer in circular and chevron impinging jets," International Journal of Heat and Fluid Flow, vol. 37, pp. 22-36, 2012.

[27] S. Discetti, A. Ianiro, T. Astarita, and G. Cardone, "On a novel low cost high accuracy experimental setup for tomographic particle image velocimetry," Measurement Science and Technology, vol. 24, no. 7, Article ID 075302, 2013.

[28] S. Ghaemi and F. Scarano, "Multi-pass light amplification for tomographic particle image velocimetry applications," Measurement Science and Technology, vol. 21, no. 12, Article ID 127002, 2010.

[29] F. Scarano, “Tomographic PIV: principles and practice," Measurement Science and Technology, vol. 24, no. 1, Article ID 012001, 2013. 

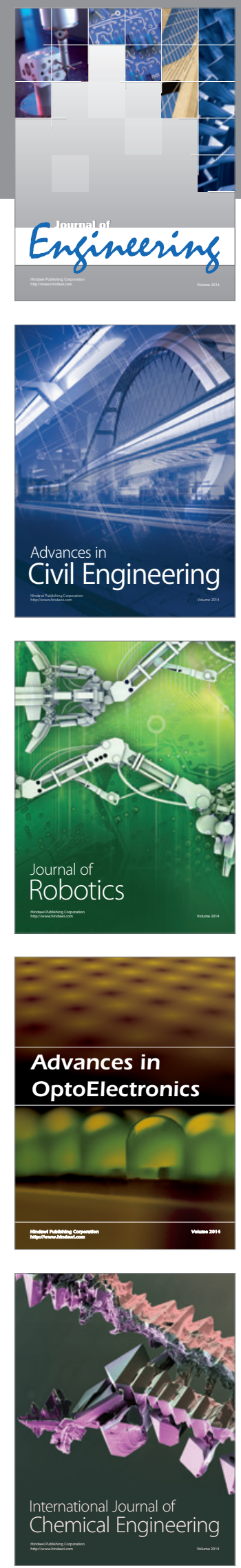

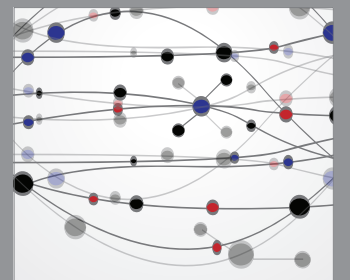

The Scientific World Journal
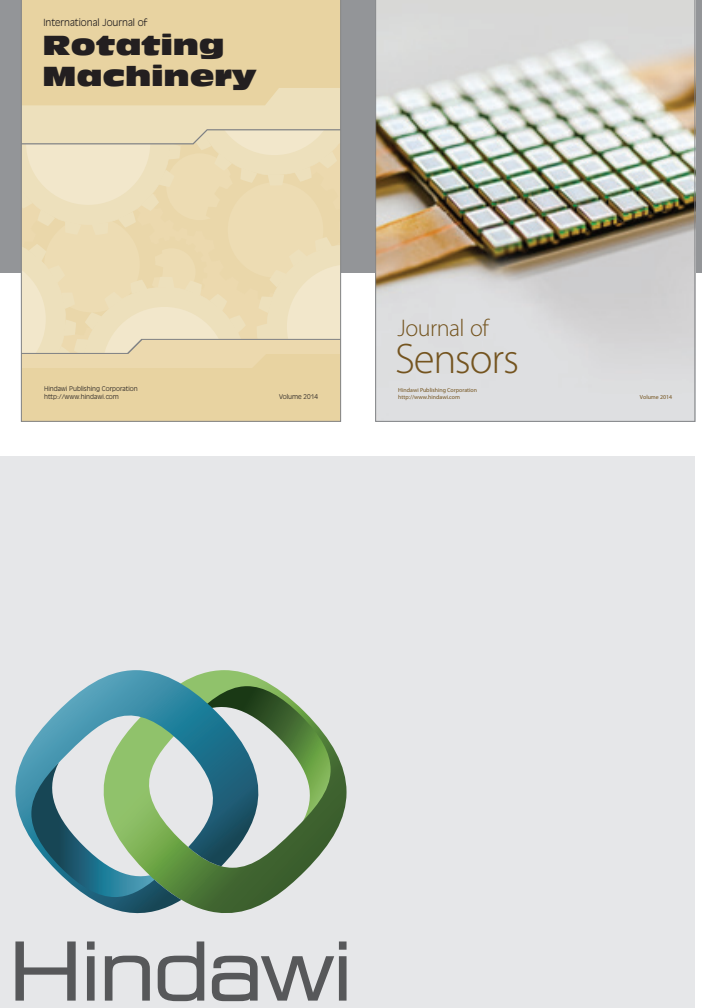

Submit your manuscripts at http://www.hindawi.com
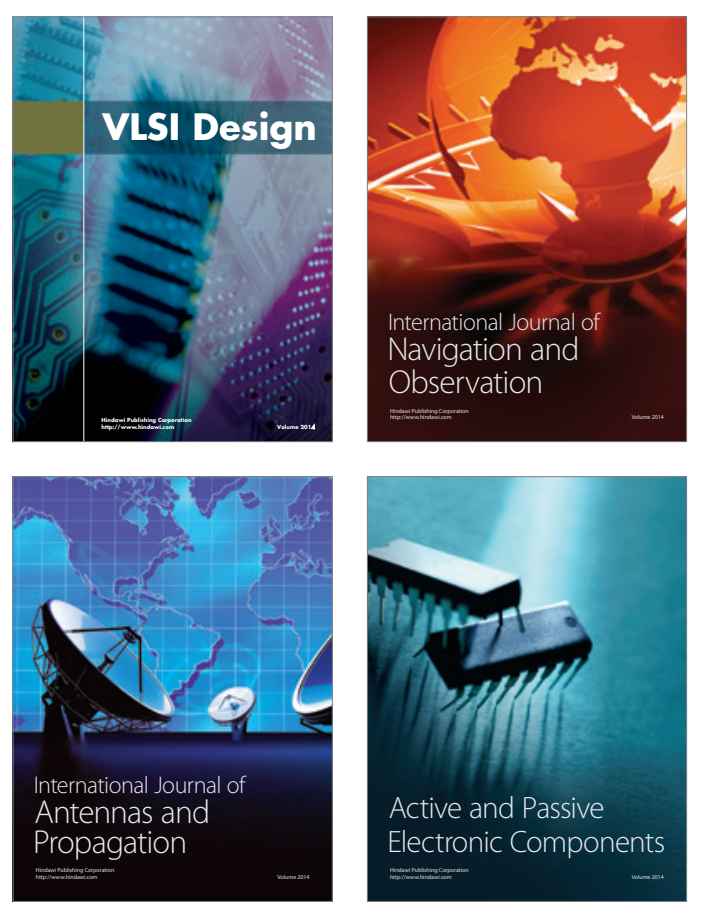
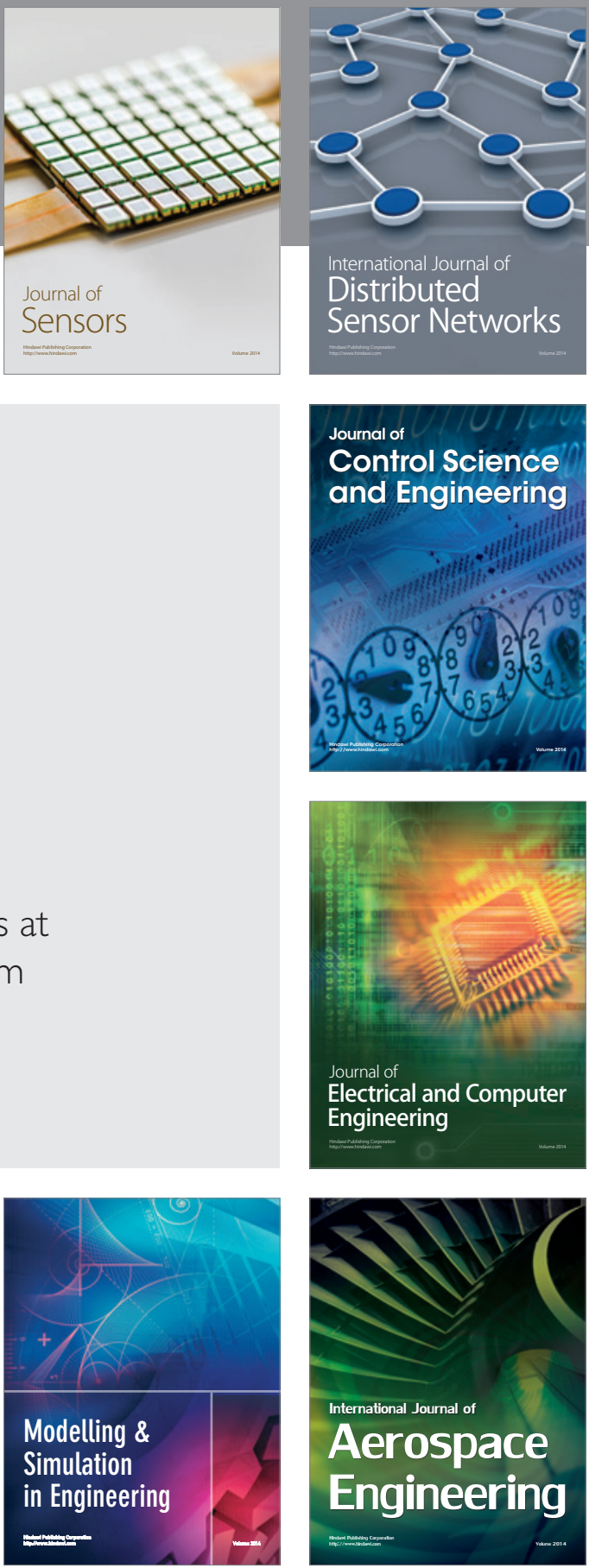

Journal of

Control Science

and Engineering
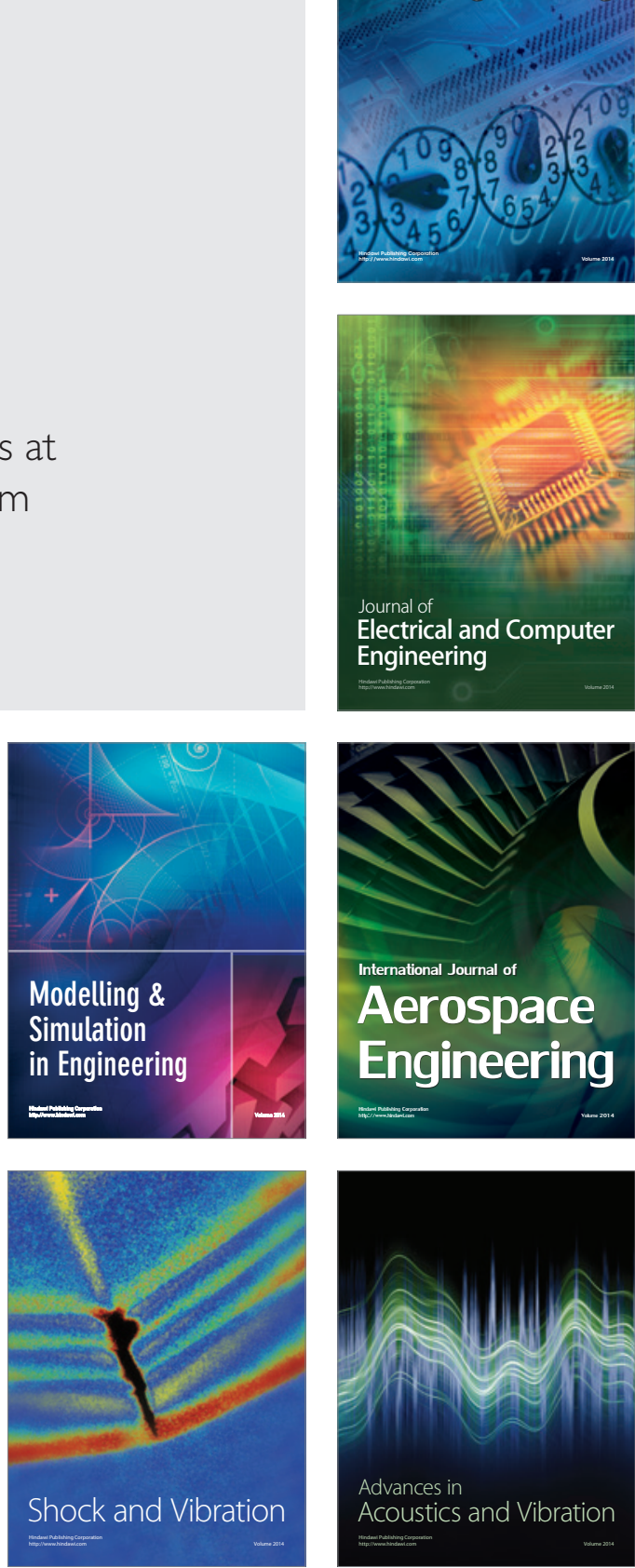